\title{
Myofibril-Inducing RNA (MIR) is essential for tropomyosin expression and myofibrillogenesis in axolotl hearts Chi Zhang ${ }^{1}$, Pingping Jia ${ }^{1}$, Xupei Huang ${ }^{1}$, Gian Franco Sferrazza ${ }^{1}$, Gagani Athauda ${ }^{1}$, Mohan P Achary'2, Jikui Wang ${ }^{3}$, Sharon L Lemanski³, Dipak K Dube ${ }^{4}$ and Larry F Lemanski*3,5
}

\author{
Address: ${ }^{1}$ Department of Biomedical Science, Florida Atlantic University, Boca Raton, FL 33431, USA, ${ }^{2}$ Department of Radiation Oncology, \\ Temple University School of Medicine, Philadelphia, PA 19140, USA, ${ }^{3}$ Department of Anatomy and Cell Biology and The Cardiovascular Research \\ Center, Temple University, Philadelphia, PA 19140, USA, ${ }^{4}$ Department of Medicine, Upstate Medical University, Syracuse, NY 13210, USA and \\ ${ }^{5}$ Department of Biological and Environmental Sciences, Texas A\&M University-Commerce, Commerce, TX 75429-3011, USA \\ Email: Chi Zhang - czhan1@med.miami.edu; Pingping Jia - p.jia@miami.edu; Xupei Huang - xhuang@fau.edu; \\ Gian Franco Sferrazza - sferrazza@scripps.edu; Gagani Athauda - g.athauda@miami.edu; Mohan P Achary - achary@temple.edu; \\ Jikui Wang - jwkr@temple.edu; Sharon L Lemanski - sharonll@temple.edu; Dipak K Dube - dubed@upstate.edu; \\ Larry F Lemanski* - lemanski@temple.edu \\ * Corresponding author
}

Published: 3 September 2009

Journal of Biomedical Science 2009, 16:81 doi:10.1186/1423-0127-16-81

This article is available from: http://www.jbiomedsci.com/content//6/I/8I

(C) 2009 Zhang et al; licensee BioMed Central Ltd.

This is an Open Access article distributed under the terms of the Creative Commons Attribution License (http://creativecommons.org/licenses/by/2.0), which permits unrestricted use, distribution, and reproduction in any medium, provided the original work is properly cited.
Received: 8 May 2009

Accepted: 3 September 2009

\begin{abstract}
The Mexican axolotl, Ambystoma mexicanum, carries the naturally-occurring recessive mutant gene ' $c$ ' that results in a failure of homozygous (c/c) embryos to form hearts that beat because of an absence of organized myofibrils. Our previous studies have shown that a noncoding RNA, Myofibril-Inducing RNA (MIR), is capable of promoting myofibrillogenesis and heart beating in the mutant $(\mathrm{c} / \mathrm{c})$ axolotls. The present study demonstrates that the MIR gene is essential for tropomyosin (TM) expression in axolotl hearts during development. Gene expression studies show that mRNA expression of various tropomyosin isoforms in untreated mutant hearts and in normal hearts knocked down with double-stranded MIR (dsMIR) are similar to untreated normal. However, at the protein level, selected tropomyosin isoforms are significantly reduced in mutant and dsMIR treated normal hearts. These results suggest that MIR is involved in controlling the translation or post-translation of various TM isoforms and subsequently of regulating cardiac contractility.
\end{abstract}

\section{Introduction}

The Mexican axolotl, Ambystoma mexicanum, has proven to be a unique animal model in the study of cardiac development. The axolotl (a neotenous salamander) carries a naturally occurring recessive mutation, gene $\mathrm{c}$, first discovered and characterized by Humphrey [1], which results in abnormal cardiac development in homozygous recessive "c/c" embryos. The mutant embryonic hearts develop, but fail to beat, making them distinguishable from normal embryonic hearts which start to beat at stage 35 . The myocytes of the mutant hearts fail to form organized myofibrils and the embryos survive only to stage 42 , the hatching stage, due to a lack of circulation.

Among the various myofibril structural proteins, tropomyosin has been shown by SDS-PAGE [2], radio-immunoassay [3], 2D gel electrophoresis [4] and 
confocal microscopy of whole hearts to be drastically reduced in the mutants [5-7]. Interestingly, other myofibril structural proteins such as actin, myosin and myosin binding protein $\mathrm{C}$, however, were found to be at or near normal levels in the mutant hearts [8-10].

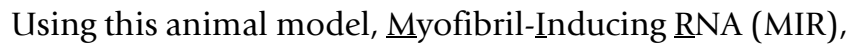
a small bioactive RNA, was shown in previous studies to be able to restore tropomyosin protein synthesis, promote myofibrillogenesis, and initiate heartbeat in the mutant embryonic hearts in organ culture [11]. The MIR appears to function through its unique secondary structure since it is a non-coding RNA $[7,11]$.

In mammals, birds and amphibians, altogether four different types of tropomyosin genes have been identified: alpha gene (TPM1), beta gene (TPM2), gamma gene (TPM3) and TM4 type gene (TPM4) [12]. More recently, TM4, a cytoskeletal tropomyosin, also has been associated with growth and regeneration in response to injury, disease state and stress in skeletal muscle of mouse and humans [13]. Moreover, in zebrafish embryos, a heart specific isoform of TM4 is essential for normal myofibril formation and developing a heartbeat [14]. In addition, it has been found recently that tropomyosin is likely necessary for actin filament formation in motile cells that employ lamellipodia and filopodia for locomotion [15]. Thus, tropomyosin appears to play a major role in actin filament modulation and contractility in both muscle and nonmuscle contractile systems. Striated muscle-specific alpha-tropomyosin is the predominant isoform in cardiac muscle, with low levels of beta-tropomyosin expressed during fetal development in the mouse heart [16]. In amphibian models, such as Xenopus, the cardiac muscle tropomyosins are synthesized from the alpha-TM and TM4 genes [17]. In all of these animal models, the alpha-tropomyosin gene is the major contributor to the tropomyosin proteins in the cardiac myofibril structures.

There are at least three striated muscle isoforms of tropomyosin present in the axolotl. Two isoforms of tropomyosin cDNA have been identified which apparently are derived from the single alpha-tropomyosin gene (TPM1) through alternative splicing [18]. Spinner et al. [19] cloned another tropomyosin CDNA which is the product of a TM4 type tropomyosin gene from axolotl heart. Our results from the axolotl model of heart development are consistent with the findings in Xenopus in that both alpha (ATmC-1 and ATmC-2) and TM4 type (ATmC-3) tropomyosin transcripts are expressed in axolotl hearts $[18,19]$.

In the present studies, we conducted a series of experiments to further understand the role of MIR in the expression of tropomyosin and myofibrillogenesis using our mutant axolotl heart model. First, we have cloned the full- length cDNA sequence of MIR. Sequence analyses suggest that MIR is a noncoding RNA molecule. However, functional studies indicate that the MIR is essential for tropomyosin expression as well as myofibrillogenesis in axolotl hearts during development at the level of translation or post-translation.

\section{Materials and methods \\ Procurement of animal tissues}

The embryos used in the study were derived from adult animals maintained in our colony. We followed NIH Guidelines for the Care and Use of Laboratory Animals and all animal protocols were approved by the Institutional Animal Care and Use Committee. Embryos at stages 35-38 were collected and dissected in Steinberg's solution (SS) as described previously [20]. The inner thoracic cavities were exposed and the hearts removed and used in the various bioassays.

\section{Bioassays with cationic liposome transfection and confocal microscopy}

Liposome reagents $(0.1-0.16 \mu \mathrm{g} / \mu \mathrm{l})$ and MIR sense $(500$ nt) $(0.022 \mu \mathrm{g} / \mu \mathrm{l})$, antisense RNA (500 nt) $(0.022 \mu \mathrm{g} / \mu \mathrm{l})$ or dsRNA (500 bp, $0.002 \mu \mathrm{g} / \mu \mathrm{l}$ ) were diluted in SS without antibiotics for $30-45$ minutes at room temperature (RT). The two solutions were mixed and drops of transfection solution were prepared. The hearts are transferred with SS into drops containing the transfection solution for a total volume of $20 \mu \mathrm{l}$ and appropriate concentrations of RNAs $(7 \mathrm{ng} / \mu \mathrm{l})$ or double-stranded RNA $(4 \mathrm{ng} / \mu \mathrm{l})$, and lipofectin. 10x of SS was added to the transfection medium to dilute the liposome reagents after 24 hours and the hearts were cultured for an additional 2 days (for mutant hearts + MIR RNA) or an additional 9 days (for normal hearts + dsRNA) in a $17^{\circ} \mathrm{C}$ incubator. The hearts were stained for immunofluorescent observation and analyzed by confocal microscopy following our previously published procedures $[7,21,22]$.

\section{Synthesis of double-stranded MIR}

Sense and antisense MIR are synthesized in vitro using T7 RNA polymerase (Ambion, TX) on PCR generated MIR cDNA templates with T7 promoter added to either 5' or 3' end sequences. $20 \mu \mathrm{g}$ of both sense and antisense RNA are mixed in annealing buffer $(\mathrm{pH} 7.4)$ and denatured at $68^{\circ} \mathrm{C}$ for 5 minutes. Sense and antisense RNAs are annealed to each other to form dsRNA by gradually reducing the temperature to $25^{\circ} \mathrm{C}$. The products were run on $1.5 \%$ agarose gels and the dsRNA was recovered from the gels. FITC-labeled dsRNA was synthesized as described above but using 1:3 FITC-conjugated UTP and unlabeled UTP for single-stranded RNA transcription. 


\section{Real-time RT-PCR}

Stage $36 / 37$ normal and mutant embryonic hearts are explanted into $15 \mu \mathrm{l}$ droplet cultures of Steinberg's buffered salt solution containing antibiotics [20]. Mutant hearts are treated with $40 \mathrm{ng} /$ heart MIR sense (166 nt) or MIR antisense (166 nt) and incubated at $14^{\circ} \mathrm{C}$ for 36 hours or 72 hours. Each treatment group consisted of 40 hearts. As controls, 40 normal and 40 mutant hearts are left untreated. The total RNA is extracted from the axolotl hearts using TRI Reagent (Sigma). Reverse transcription is performed using the Thermoscript RT system from Invitrogen, CA. Quantitative PCR is performed in a Lightcycler system using a Roche's Fast Start SYBR Green I Kit, following our published methods [23]. The primers were

Table I: Primers used for different genes in real time RT-PCR experiments.

\begin{tabular}{|c|c|c|c|}
\hline Gene & Forward/Reverse & Primer Sequence & Product Size \\
\hline ATmC-3 & Forward & 5'-ggagcttgaccatgcgctgaa & 200 \\
\hline ATmC-3 & Reverse & 5'-tgagaaccgacacaaagcaagagg & \\
\hline ATmC-exon2a & Forward & 5'-gcgtgacagggtgctggatgaac (P5) & 154 \\
\hline ATmC-exon2b & Forward & 5'-tgaagggtaccgaggacgagttgga (P3) & \\
\hline ATmC-exon3 & Reverse & 5'-ccagacgctcctgagcacgatcc (P4) & \\
\hline ATmC-exon345 & Forward & 5'-gagcgtctggccacagccctaca (PI) & 233 \\
\hline ATmC-exon345 & Reverse & 5'-tcttccgcacgctccagatcacc (P2) & \\
\hline ATm5- & Forward & 5'-gccacacctacctgcgagtgttcc & 249 \\
\hline ATm5- & Reverse & 5'-gacgctcctgagcacgatccaac & \\
\hline MIR & Forward & 5'-ttccacccactcgagcgtcaaca & 158 \\
\hline MIR & Reverse & 5'-gctcggatatgcgtgcaaccttga & \\
\hline cTnT & Forward & 5'-ccaagggcttcaccgggctcaa & 173 \\
\hline cTnT & Reverse & 5'-tggcagaggtggaatggatcacagg & \\
\hline$\alpha$-syntrophin & Forward & 5'-ggactctccaccgectccctctc & 208 \\
\hline$\alpha$-syntrophin & Reverse & 5'-ccccgcttcatccttcgctctga & \\
\hline$\beta$-syntrophin & Forward & 5'-gacttggcttggtgggctgaacg & 243 \\
\hline$\beta$-syntrophin & Reverse & 5'-aggccattcagttgcagggtgct & \\
\hline Msxl & Forward & 5'-tgtacgccgctcacatgggctac & 220 \\
\hline Msxl & Reverse & 5'-ccctcttcctgccaccgaatcac & \\
\hline Msx2 & Forward & 5'-ggaagggaagggaaggcagaacg & 215 \\
\hline Msx2 & Reverse & 5'-tccacgaatcagggcgttgtttg & \\
\hline$\beta$-actin & Forward & 5'-tccatgaaggctgcccaact & 210 \\
\hline$\beta$-actin & Reverse & 5'-tggcgccacatctgattgat & \\
\hline
\end{tabular}


designed by the Primer 3 program from the Massachusetts Institute of Technology as listed in the Table 1.

\section{Cloning of exon Ib sequence for axolotl alpha-TM}

We have cloned exon 1b of the axolotl alpha-TM. 5'RACE experiments using primers designed from the exon 3 sequence of the axolotl alpha-TM (ATmC1-exon3-rev-1: 5'-CCAGACGCTCCTGAGCACGATCC; ATmC1-exon3rev-2:5'-CCAGCTGGATACGCCTGT TC) and a 5' adaptor sequence revealed both PCR bands corresponding to the ATmC-1 sequence and a shorter PCR band after agarose gel electrophoresis. The shorter band was cloned into a pGEM-T easy vector (Promega, WI) and sequenced. The sequence shows high homology to the 5 ' ends of alphaTM5a or 5b from other vertebrates. The sequence is: 5 'GTACTGTTGAGGCATCCACGTCTTCACTATTACT-

GGGGCATTTGTAGTCCCTTGGAATTTGAG CTGACCTTATCGCTACTCGCCTCATATGATAGAGGCGCCACACCT ACCTGCGAGTGTTCCGTT CCCCGGCCCTCAGCATGTCTGGGGGCACCTCCCTGGAAGCGGTGCGGCGGAAGATCCGCGC CCTGCAGGAGCAGGCGGACTCCGCTGAAGCCCGGGCGTGTAGCCTGCAGCGGGAACGAGAC GCTGAGCGGCAGCTGCGAGAGGCGGCTGAGAGTGATGTA GCCTCCCTGAACAGGCGTATCCA GCTGGTTGAGGAAGAGTTGGAT CGTGCTCAGGAGCGTCTGG. The bolded ATG represents a putative translation start site. The cloned sequence corresponding to exon 3 shows $100 \%$ identity to alpha-TM but with variations to axolotl ATmC-3, demonstrating the origin of this fragment from axolotl alpha-TM. We have named this isoform ATm5.

Two-dimensional gel electrophoresis and Western blotting Isoelectrical focusing

The immobilized $\mathrm{pH}$ gradient (IPG) gel strips ( $\mathrm{pH}$ range 3-6, $11 \mathrm{~cm}$, Bio-Rad, CA) were rehydrated in $200 \mu \mathrm{l}$ ReadyPrep Rehydration/Sample Buffer that contained heart samples for 12 hours. Isoelectric focusing (IEF) was performed on the rehydrated IPGs at $20^{\circ} \mathrm{C}$ in three steps: 250 volts for 20 minutes, 8,000 volts for 2.5 hours, and then 20,000 Volts/hour using Protean IEF Cell system (BioRad, CA).

\section{Two-dimensional SDS-PAGE}

After isoelectrical focusing was completed, IPG strips were prepared for SDS-PAGE using 12\% Bis-Tris precast gels (Bio-Rad, CA). The strips were then rinsed with electrophoresis running buffer (pH7.7) and laid into the twodimensional well of $12 \%$ precast gels and were run at 200 $\mathrm{V}$ for 1 hour following the manufacturer's protocol (ReadyPrep $^{\mathrm{TM}}$ 2-D Starter Kit; Bio-Rad, CA.).

\section{Western blotting}

The two-dimensional SDS-PAGE gels were transferred to nitrocellulose membranes and processed for hybridiza- tion. The membranes were incubated with $\mathrm{CH} 1$ monoclonal antibody (1:5000) (from Developmental Studies Hybridoma Bank, University of Iowa) at a 1:2000 dilution for 1 hour at RT. After two washings for 5 minutes each, they were hybridized with horseradish peroxidase-conjugated mouse antihuman IgG (Amersham-Pharmacia Biosciences) at 1:5000 dilution for 1 hour at RT and the blots were washed and exposed to X-ray film and developed with an ECL chemiluminescence system [22].

\section{Results \\ Cloning the full length cDNA of the myofibril-inducing RNA (MIR) gene}

We have previously published the nucleotide sequence of the $166 \mathrm{nt}$ long bioactive MIR [11] and showed that the artificially synthesized $166 \mathrm{nt}$ RNA can promote myofibril formation and initiate beating of the mutant hearts in organ culture studies [11].

To determine the full length sequence of the MIR gene, we carried out experiments using a cDNA lambda phage library from axolotls at stage 15-17 as well as an axolotl genomic library (Stratagene, TX). Primers were designed, based both on vector flanking sequences and the $166 \mathrm{bp}$ known fragment of the MIR. The PCR products were confirmed by Southern blotting assays. The promising PCR bands were then sub-cloned into pGEM-T vectors (Promega, WI) and subsequently sequenced. Primers were designed again based on the new sequence and PCRs were repeated (Table 1). By using genomic walking we have extended the 5'-end of the original 166 bp MIR to 700 bp. Starting from the original 166 bp MIR known sequence, we also have performed 5' RACE reactions using a Smart RACE Kit (Ambion, TX). Results show that the full length of the MIR is expressed beginning at G (380 th base) within the genomic sequence (Fig. 1). In addition, 3' RACE reactions have revealed about $150 \mathrm{nt}$ poly-A tail attached at the 3 ' end of the MIR (Fig. 1). We believe that we have successfully cloned the full length MIR. The nucleotide sequence of MIR has been determined and found to be unique because there is no significant homology with other known sequences available from the gene databases. Moreover, there is no relatively large open reading frame in the full-length sequence, indicating that the MIR may be functioning directly through its RNA structure, rather than a translation product. Interestingly, eukaryotic promoter prediction software (ExPASy: http://ca.expasy.org/tools/) has localized a potential promoter in the $5^{\prime}$ genomic sequence with a conserved TATA box, 28 bp from the transcription start site (Fig. 1). Our recent data using the Luciferase reporter gene system (Promega, WI) have verified the transcription driving ability of this potential promoter. We have cloned nearly $3 \mathrm{~kb}$ of the upstream regulatory sequence in addition to the promoter sequence shown in Fig. 1. Serial dele- 

TTAAGGATAGCATCACAAGGTGTATACCCCAGGATGGAACATTGGATCTA AGGAGGATCACAGACTAGTCATACCTGGAACGCTCTGTCAGACCAGAGGA CATAAAAGACTTTCAGGTTTGAGACGCAGACGTTGGAATGAGTTGCCCAA GTTCTGCTCATGACAACACCTGCTTTCAGGCCCCTGTTGGAGCATCATCT GTTCAGGTAGGTGTTCATTAATGGTCTCTAGCAGACCCAAGATCAGTGTG CACAAGCACATGATTTCACAAAGGTGATATATGGGTAGGTTCTATGTAAA AACACTGCAAA T TCTAACATCACCCAATGTTCAAAAATAACATTT TAAT TTTGTATCTCCTAATACAGCCATCATAACATATTCTAGGACTGGTATAAC TGTATAGACAAACTCCCTTCCTAGGATATTTTGGGAAAGTGCTGGATAGC CGGGGAGAACAGCACCTTTCTCTCAGGCAATGTTAAATAGGTGCAATGTT TTCACATGTTATGGAATATATCTTCCAACTGACTGACCAAGAGAAAACAA TGAACCACAATACCGGAAACTTCATTCGTTTGACCCTTCCACCCACTCGA GCGTCAACATGCCCAGGCCGCTACCCCTTGACACACGTGTAGCACCACTC CATTTTTGGAACACCTCCTCTACCGTGGATGAGAGGCGGA GCCGATCCTT TGGAATTTGTACATGTGACCTCAAGGTTGCACGCATATCCGAGCAGTTGC TGGATTAGAGCAGGCACTCCCTTATCGGCTTTGGAATGGAGACCAGAAAG AACAATGTGGGACAGCTGATATGGAGGGCAGGGCGGGGAAGTGAGAGAAA GGGCAACAATAGAGGGCAGATAAAGGGGGGAGGGCAAGGAATAAACAGGA

\section{Figure I}

The full length sequence of the MIR gene. Genomic DNA sequence: I-379 bp (Underlined); Active MIR sequence (I66 $\mathrm{nt}): 69 \mathrm{I}-856 \mathrm{bp}$ (Bold and underlined); Potential polyadenylation signals: 835-840 bp and 840-845 bp; Predicted TATA box: 343-350 bp (Shaded); Longest predicted open reading frame: 659-808 bp; Poly A+: $977-1000$ bp.

tions of the promoter have been inserted into the Luciferase reporter vectors and expression of these promoters has been confirmed by transfecting into rat neonatal cardiomyocytes in culture (our unpublished data).

\section{Full length MIR promotes tropomyosin protein expression} in cardiac nonfunction mutant embryonic hearts

In vitro synthesized sense RNA from the full length (570 nt) MIR gene showed significant rescuing ability of the mutant hearts (Fig. 2). Three days after sense MIR transfection, all of the 40 dissected mutant hearts showed positive tropomyosin staining (Fig. 2C) while antisense RNA transfection showed only background levels of staining (Fig. 2D). Pretreatment of the MIR sense RNA with RNase before transfection into the mutant hearts totally abolished the activity of the sense RNA in promoting tropomyosin expression (Fig. 2E). It is clear that the bioactivity of promoting tropomyosin expression in the mutant hearts is due specifically to the sense MIR. These results are in total agreement with our previous findings using the short version of the MIR (166 nt). The full length $570 \mathrm{nt}$ RNA used for transfection in current experiments is at the same molar concentration as the $166 \mathrm{nt}$ RNA we used for previous studies [7,11]. Since the original 166 nt RNA (partial sequence from MIR gene) is sufficient for the rescuing of mutant hearts (Fig. 2F) $[7,11]$, we believe that the $166 \mathrm{nt}$ partial sequence probably is the functional bioactive unit in the MIR gene.

\section{MIR-promoted tropomyosin protein expression in the mutant hearts is not due to increased transcription levels or splicing pattern changes of tropomyosin genes}

To determine whether MIR-promoted tropomyosin protein expression in the mutant heart is due to regulation at the transcriptional levels or changes in the splicing patterns of the TM transcripts, we proposed two hypotheses. 

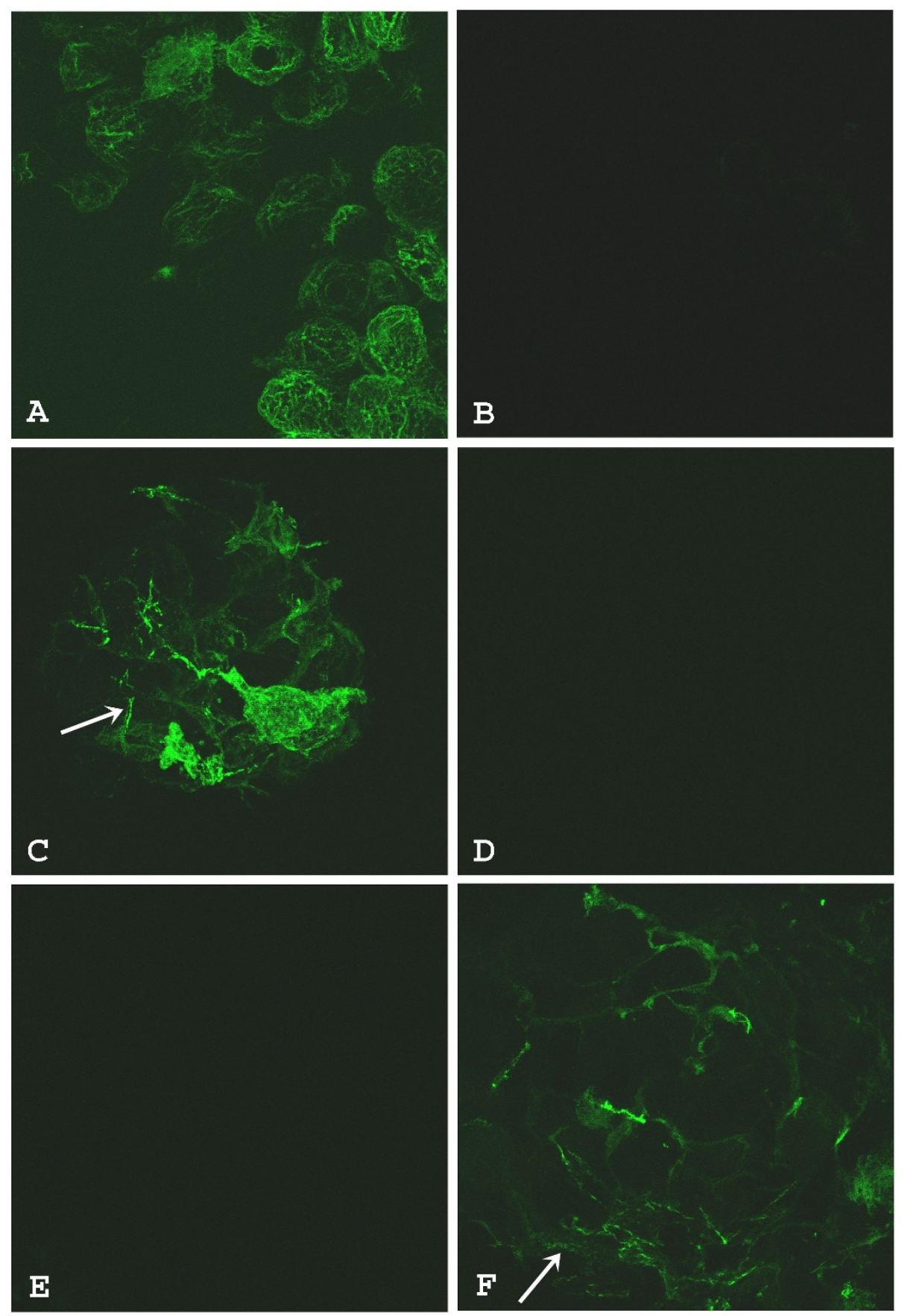

\section{Figure 2}

Confocal microscopy of embryonic axolotl hearts stained with anti-tropomyosin antibody. Normal heart incubated with Steinberg's solution and lipofectin only has extensive tropomyosin staining (A). Mutant heart incubated with Steinberg's solution and lipofectin only has virtually no staining (B). Mutant heart incubated with Steinberg's solution, lipofectin and full length sense MIR shows significant tropomyosin (arrow) staining (C). Mutant heart incubated with Steinberg's solution, lipofectin and full length sense MIR pretreated with RNase. Very little tropomyosin is indicated in the cells (D). Mutant heart incubated with Steinberg's solution, lipofectin and full length antisense MIR. No staining for tropomyosin is observed (E). Mutant heart incubated with Steinberg's solution, lipofectin and $166 \mathrm{nt}$ MIR RNA shows significant levels of tropomyosin (arrow) protein (F); Magnification: $60 \times$. 
We tested those hypotheses by performing a series of realtime RT-PCR experiments.

Our first hypothesis proposes that for the MIR to promote tropomyosin protein expression, it must increase the expression of one or both of the tropomyosin genes (alpha-tropomyosin and TM4 type) at the transcription level. For the real-time RT-PCR experiments, we designed primer pairs to amplify the alpha-tropomyosin and TM4 type tropomyosin genes selected from the common exon sequences whose products represent the total transcripts of each gene (Table 1). For alpha-TM, primers (ATmC345-for and ATmC-345-rev) are designed in the Exon 3, 4 and 5 regions which are common to all alpha-TM transcripts $[24,25]$; for TM4 type tropomyosin, primers (ATmC-3-for and ATmC-3-rev) are designed in the 3' UTR region (Fig. 3A, B). Our real-time PCR results clearly show that there is no significant difference between alpha-tro- pomyosin or TM4 type tropomyosin RNA transcripts in normal $(+/+)$, mutant $(\mathrm{c} / \mathrm{c})$, sense MIR- and antisense MIR- treated mutant embryonic hearts (stage 37-38) at two different time periods of the transfection of MIR (Fig. 4A1, A2). These results clearly demonstrate that the MIR does not perform a regulatory function at the transcriptional level, thus disproving the first hypothesis.

Our second hypothesis proposes that the MIR regulates splicing of tropomyosin transcripts to produce correct isoforms in the cardiac muscle cells. For these real time RTPCR studies, we designed specific primer pairs based on representative alternative spliced exons of the alpha-tropomyosin gene. From our previous studies, we found that both ATmC-1 and ATmC-2 CDNAs are expressed from the same alpha-tropomyosin gene but differ in exon 2, with ATmC- 1 containing a striated muscle specific exon $2 b$ while ATmC-2 contains a smooth muscle isoform specific

\section{A. alpha-TM gene:}
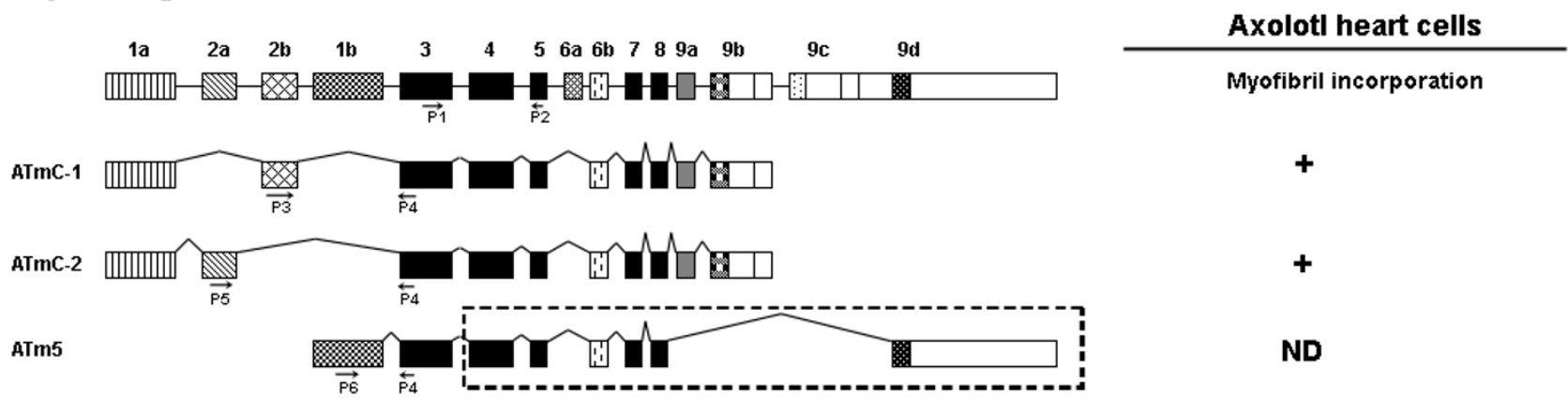

\section{B. TM4 gene:}

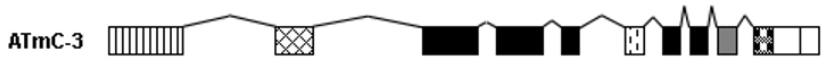

\section{Exon 1b comparison between axolotl alpha-TM gene (in ATm5) and other vertebrate alpha-TMs}

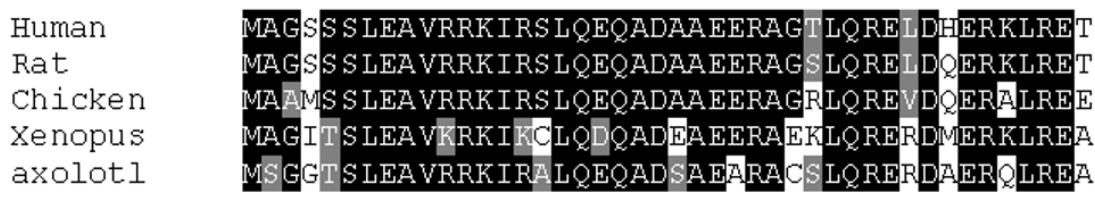

Figure 3

Schematic representation of four different TM isoforms produced from alpha -TM (A) and TM4 type tropomyosin (B) genes. Each box represents an exon which is joined together by mRNA splicing. The alpha-TM gene is alternatively processed at both the $5^{\prime}$ and/or $3^{\prime}$ ends, as well as at the internal exons $6 \mathrm{a} / \mathrm{b}$. Our studies are focused on the $5^{\prime}$ end sequence and exon $2 \mathrm{a} / \mathrm{b}$. The fibroblast type tropomyosin isoform (ATm5) has only the 5 ' sequence cloned with exon Ib and part of exon 3 cloned for RT-PCR studies, assuming the internal and 3' sequence are homologous to other vertebrates (dashed line box). Primers to amplify specific isoforms were designed based on the alternative spliced exons (PI to P5). C. Highly conserved peptide sequence from exon Ib of axolotl alpha-tropomyosin compared to other vertebrate sequences. The indicated splicing pattern of axolotl tropomyosin genes are hypothetical based on other vertebrate sequences. ATmC-I, 2 and 3 were all demonstrated to be able to incorporate into myofibril structures [2I]. 

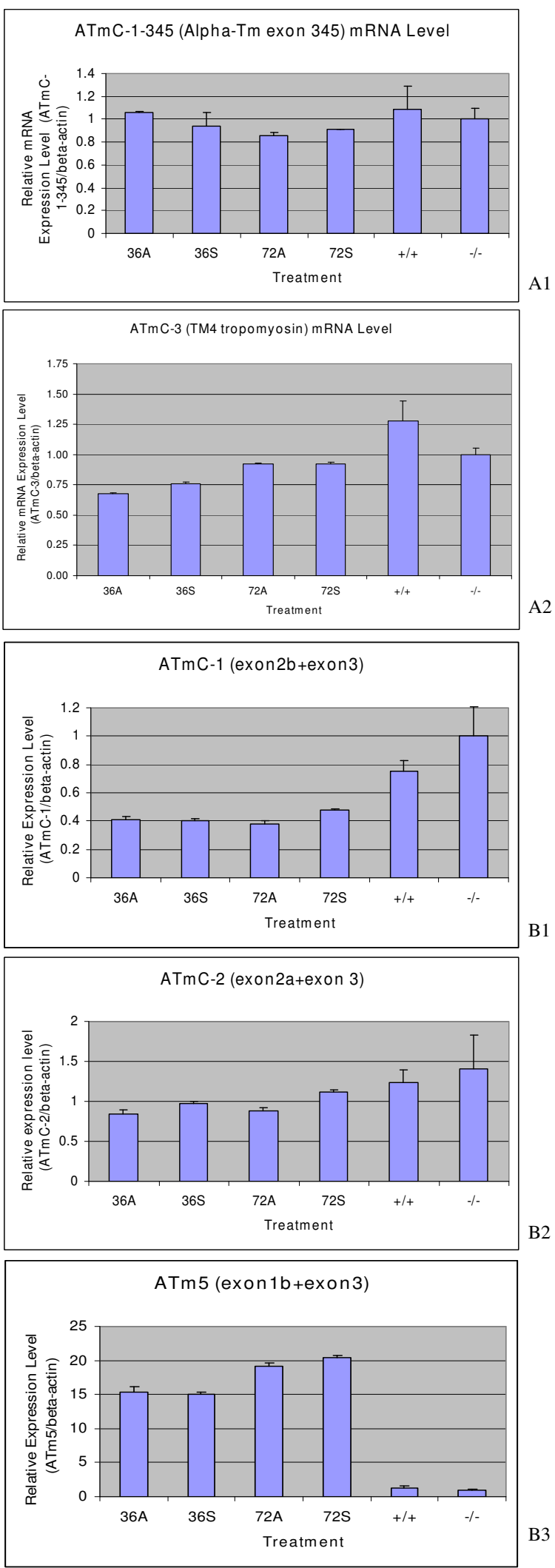

Figure 4

\begin{abstract}
Figure 4
Transcriptional levels of various tropomyosin isoforms (AI and A2); Determination of mRNA splicing of various tropomyosin isoforms (B , B2 and B3). Real-time RT-PCR showed no significant difference at the transcription level for alpha- (AI) and TM4 type tropomyosin (A2) genes in the mutant hearts treated with MIR sense or antisense RNA. 36A: Mutant hearts treated with antisense MIR for 36 hours; $36 \mathrm{~S}$ : Mutant hearts treated with sense MIR for 36 hours; 72A: Mutant hearts treated with antisense MIR for 72 hours; 72S: Mutant hearts treated with sense MIR for 72 hours; +/+: homozygous normal hearts with no treatment; (-/-): homozygous mutant hearts with no treatment. Real-time RT-PCR showing no significant difference during mRNA splicing of the alpha-TM gene (the ATmC-I containing exon $2 \mathrm{~b}(\mathrm{BI})$, the $\mathrm{ATmC}-2$ containing exon $2 \mathrm{a}(\mathrm{B} 2)$ and the fibroblast tropomyosin isoform with direct exon $I b$ and 3 conjunction (B3) in the mutant hearts treated with the MIR sense or MIR antisense.
\end{abstract}

exon 2a (Fig. 3A). We have shown previously that both ATmC- 1 and ATmC-2 can be incorporated into cardiac muscle fibers [21]. Alpha-TM has been reported also to produce fibroblast tropomyosin isoforms with smaller molecular weights, such as TM5a and TM5b, both of which can be incorporated into myofibrils [25]. Isoforms TM5a and 5b are produced by using an internal promoter located between exon $2 \mathrm{~b}$ and exon $1 \mathrm{~b}$ thus skipping exon $2 \mathrm{a}$ and exon $2 \mathrm{~b}$ and conjoining exon $1 \mathrm{~b}$ and exon 3 directly together [26]. To determine whether MIR can regulate the expression pattern of tropomyosin by selectively favoring the use of exon $1 \mathrm{~b}, 2 \mathrm{a}$ or $2 \mathrm{~b}$, we have cloned exon $1 \mathrm{~b}$ of the axolotl alpha-TM to study the Axolotl Tm5 gene (ATm5). 5' RACE experiments using primers designed from the exon 3 sequence of axolotl alpha-TM and a $5^{\prime}$ adaptor sequence revealed PCR bands corresponding to the ATmC-1 sequence and a shorter PCR band by agarose gel electrophoresis. The shorter PCR band was gel purified and cloned into T-vectors (Promega, WI). Sequencing results demonstrated a highly conserved sequence of axolotl alpha-TM exon 1 compared to other vertebrates (Fig. $3 \mathrm{C})$. We then designed different primer pairs based on the alpha-TM exon $1 \mathrm{~b}, 2 \mathrm{a}$ and $2 \mathrm{~b}$ sequences (Fig. 3A). Realtime RT-PCR was performed on normal, mutant, MIR sense and antisense RNA-treated mutant embryonic hearts using these primer pairs to compare alpha-TM splicing patterns. Results from these experiments did not support our second hypothesis. That is, the alpha-TM splicing pattern at the $5^{\prime}$ end is not regulated by the MIR. Neither ATmC-1 (exon 2b included) nor ATmC-2 (exon 2a included) type splicing is altered with MIR treatment (Fig. 4B1, B2). Similar quantities of splicing products also were observed for fibroblast type tropomyosin with direct 
exons $1 \mathrm{~b}$ and 3 conjunctions in all normal, mutant, MIR sense and antisense RNA treated hearts (Fig. 4B3).

Thus these studies reiterate that MIR-promoted tropomyosin expression in the mutant hearts is not due to increased transcription levels or splicing pattern changes in the tropomyosin genes.

\section{Knockdown of MIR expression decreases sarcomeric tropomyosin protein resulting in the failure of myofibril formation in normal hearts}

Our confocal immunofluorescence studies have proved that MIR is sufficient to promote tropomyosin expression and myofibrillogenesis in cardiac mutant hearts. To demonstrate that the MIR is essential for normal embryonic heart development in axolotls, double-stranded MIR (550 bp covering the full length) was synthesized as described in the Materials and Methods section. Successful production of double-stranded MIR (dsRNA) has been verified by polyacrylamide gel electrophoresis (Fig. 5). Using the same methods, we have also produced FITC-labeled dsRNA. The high transfection efficiency using these dsRNAs was demonstrated by confocal microscopy. It showed nearly $100 \%$ of the heart cells in the embryonic heart tube were transfected using our transfection protocol. The double-stranded RNA was purified from single stranded RNA residue by agarose gel electrophoresis and was applied to the cultured normal whole embryonic hearts. We found that this RNA was effective in inhibiting the normal heartbeat as determined by daily evaluation under a dissecting microscope (Table 2). Monoclonal antibody staining (CH1) for tropomyosin $[7,27]$ in these double-stranded RNA-treated hearts revealed disruption of myofibril formation (Fig. 6).

The dissected normal hearts with mock transfection (no RNA) showed abundant tropomyosin expression and organized myofibrils easily detectable by confocal microscopy even after 9 days in culture (Fig. 6A). Most doublestranded MIR-transfected hearts (22 out of 30 total hearts at stage 37) when dissected stopped beating after 4 days in culture. Careful observation of these hearts under an inverted microscope $(\times 200)$ revealed sporadic contractions in portions of the heart tube indicating that these hearts have live tissue. We evaluated the viability of the cells in the organ-cultured hearts by staining the whole hearts with Trypan Blue. Interestingly, 9 out of the $22 \mathrm{ds}$ MIR-transfected hearts that had stopped beating, resumed contraction activity after 6 days in culture although at a decreased beating rate and strength, while the rest remained quiescent for the duration of the experiment ( 9 days). Confocal microscopy on these hearts that stopped beating and never regained their contractility after 9 days in culture showed a significant disarray in the myofibril structures and decreased levels of tropomyosin protein

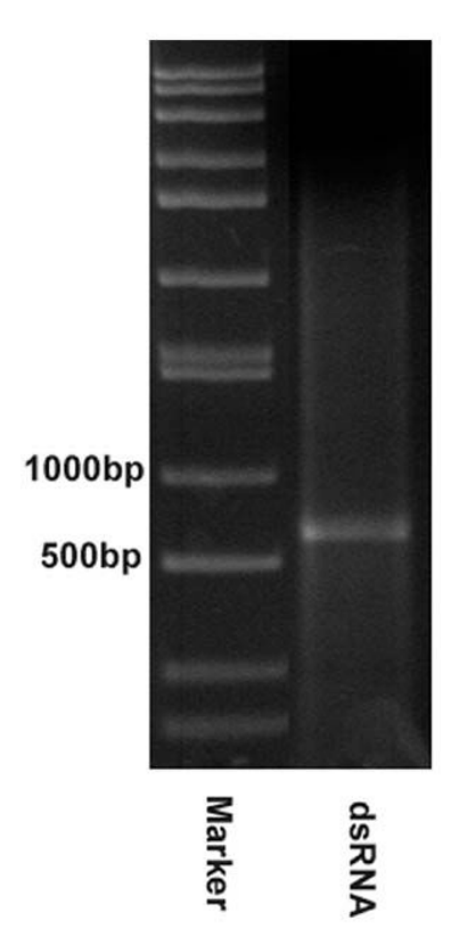

Figure 5

Double-stranded MIR. Synthesized MIR double-stranded RNA loaded on I.5\% agarose gel for electrophoresis shows a 550 bp band. The size marker is loaded on the left-side of the gel.

expression (Fig. 6B), similar to the untreated mutant hearts $[7,21]$. No rescuing effect was observed in the mutant hearts transfected by ds RNA and also they showed a negative staining pattern for tropomyosin expression (Fig. 6C). A mock-transfected (no RNA) normal heart showed numerous cells positively stained by tropomyosin antibody, CH-1 (Fig. 6D). Fig. 6E shows a normal heart treated with double-stranded MIR. It clearly showed significantly lower tropomyosin expression than normal levels in the whole heart tube except for the conus region, which showed a few positively stained cells. Results are reminiscent of a similar staining pattern for mutant hearts in our previously published study [21], with negative staining for tropomyosin in the ventricle but positive staining in the conus region. Since ds RNA could be degraded by Nuclease S1 [28], we also included a control group of normal hearts transfected with dsRNA predigested with Nuclease S1 (Promega, WI) in our experiments, to determine whether degraded double-stranded RNA has any effect on normal heart beating. Interestingly, after transfection with the degraded double-stranded RNA, these hearts stopped beating temporarily (possibly due to the damaging effects of RNases remaining in the medium) but regained normal beating activity after an additional 3 days in culture. Confocal microscopy showed 

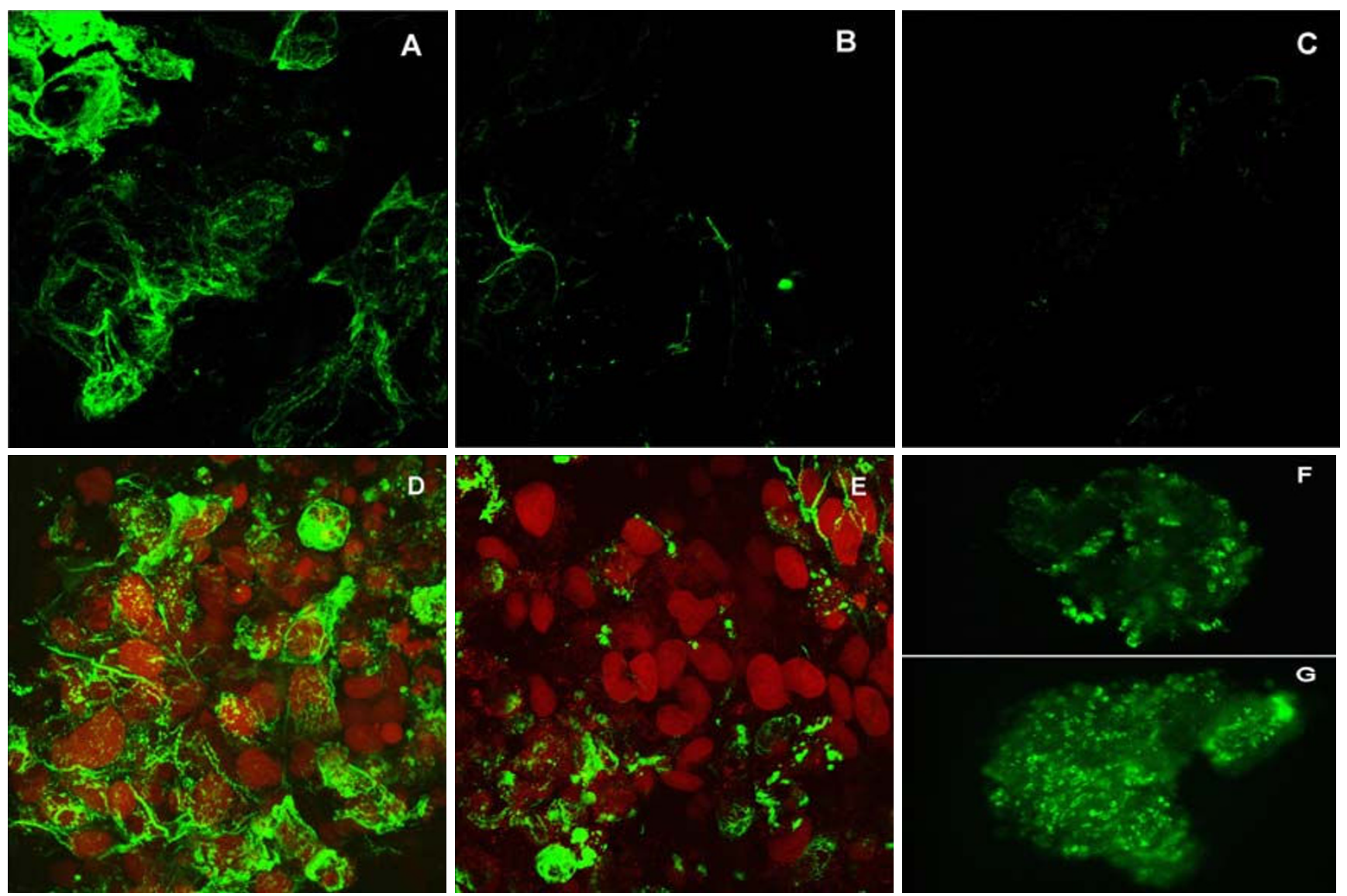

\section{Figure 6}

Confocal microscopy of embryonic axolotl hearts treated with double-stranded MIR. The images show those hearts that stopped beating after 4 days but regained contractions later. Hearts were fixed after 9 days in culture. Normal heart (stage 36) organ cultured with lipofectin in Steinberg's Solution only for 10 days (A); Myofibril structures are clearly shown. Normal heart (stage 36) organ cultured with lipofectin in Steinberg's Solution with double-stranded RNA for 10 days (B); Mutant heart (stage 36) organ cultured with lipofectin in Steinberg's Solution with double-stranded RNA for 10 days (C). (Magnification: A-E: $60 \times$; F and G: $10 \times$ ). Hearts incubated with mock transfection (no dsRNA) show abundant staining of tropomyosin and organized myofibril structures $(\mathrm{D})$ with nuclei stained by propidium iodide (PI). Hearts transfected by the dsRNA show a significant decrease of tropomyosin expression in more than half of the cells but continue to express in the remaining cells (E). Normal hearts treated with dsRNA for 9 days stained for tropomyosin (F). Clusters of cells with positive staining for tropomyosin are present in different areas. Normal hearts with mock transfection (no dsRNA) for 9 days stained for tropomyosin $(G)$.

Table 2: Percentage of beating hearts at different time points after ds RNA transfection.

\begin{tabular}{lccc}
\hline Treatment Groups & Day 0 (0 hr) & Day 4 (96 hrs) & Day 9 (2 I6 hrs) \\
\hline dsRNA treated group & $100 \%$ & $26.67 \%$ & $46.67 \%$ \\
\hline RNase-pretreated dsRNA treated group & $100 \%$ & $76.67 \%$ & $70 \%$ \\
\hline Steinberg's solution only group & $100 \%$ & $96.67 \%$ & $76.67 \%$ \\
\hline
\end{tabular}


numerous positively-stained cells in these hearts which appeared similar to untreated normal hearts after 9 days in culture.

In the double-stranded MIR RNA treated normal hearts that stopped beating after 3 or 4 days but regained contractions after 9 days, confocal microscopy studies still revealed decreased staining of tropomyosin protein (Fig. 6F) compared to mock transfected cells (Fig. 6G). Organized myofibrils with tropomyosin staining could be found in a few sparsely distributed cells in the heart although the overall numbers of stained cells were dramatically decreased in the dsRNA-treated hearts (Fig. 6E) compared to the control normal hearts without dsRNA treatment (Fig. 6D). Since our whole-mount heart specimens are usually 150-200 $\mu \mathrm{m}$ in thickness, we used epifluorescence microscopy to view the fluorescence image of the whole heart. Thus we were able to clearly observe the groups of cells that show positive staining in the dsRNA-treated whole hearts (Fig. 6F, G).

Immunofluorescence confocal microscopy also has showed the decrease in tropomyosin expression in normal hearts that stopped beating after transfection with double-stranded MIR for 4 days. In some of the hearts, the loss of cells with positive tropomyosin protein staining and organized myofibrils structure is nearly $100 \%$ in the ventricular area of the heart tube (Fig. 7A, B). We observed some cells in a random pattern that have positive green signal from tropomyosin staining, but with a much lower signal intensity. In hearts that stopped beating after 4 days of transfection with double-stranded MIR, their tropomyosin staining was much weaker in general and there were far fewer cells with positive staining for tropomyosin as compared to the hearts from day 9 . The high percentage of cells with decreased tropomyosin expression in the whole heart tube after double-stranded MIR transfection is due to our high efficiency of transfection of double-stranded MIR into the heart cells, as described in the Materials and Methods section. The efficiency in knocking-down tropomyosin expression as well as visualization of its differential expression was likely due to direct exposure of cardiomyocytes to the MIR in solution because of an absence of the epicardial layer in hearts at stage 37/38 [29].

These findings strongly suggest that the MIR gene is essential for myofibrillogenesis and heart development in normal embryonic hearts.

The transcription levels of ATmC-I and 2 (alpha-TM) and ATmC-3 (TM4) genes are not altered by short term but
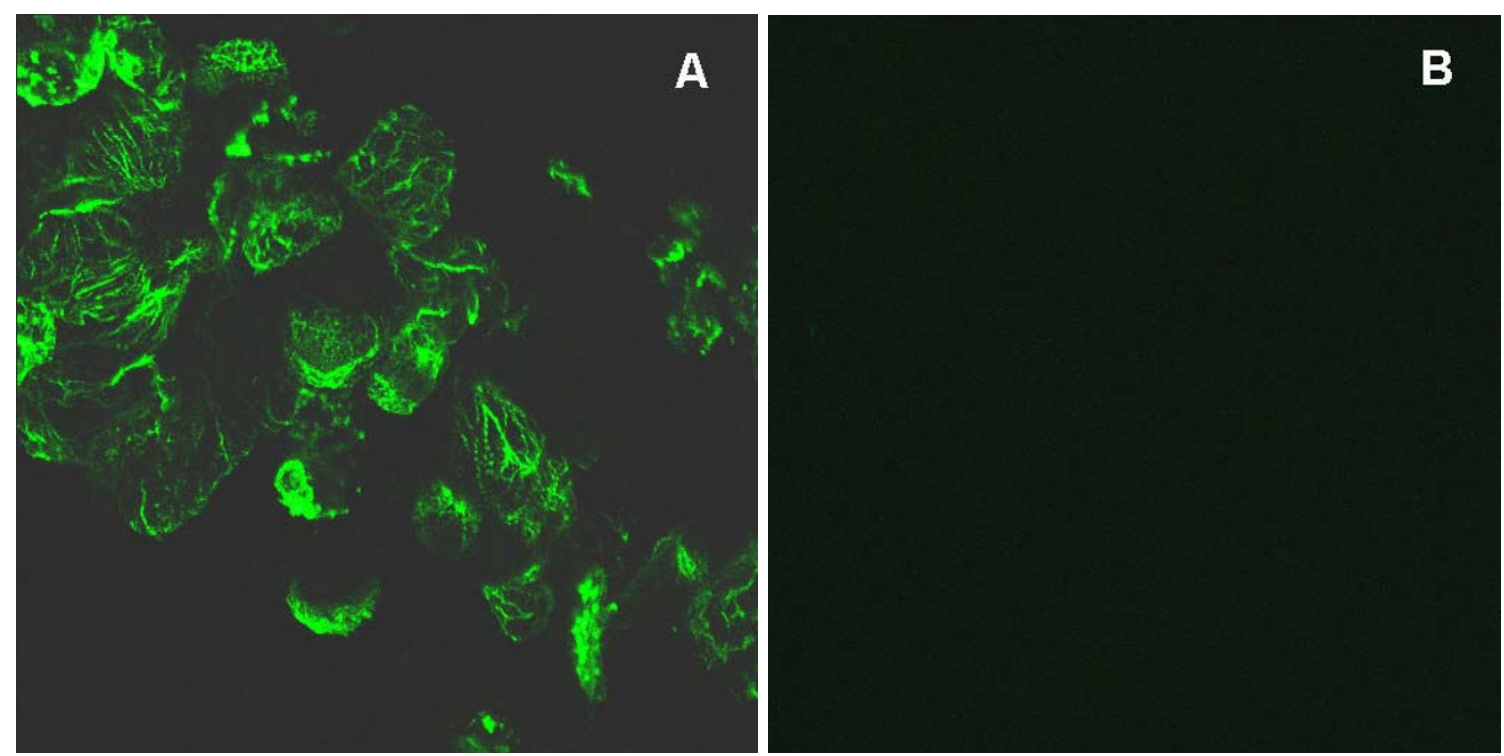

\section{Figure 7}

Myofibril morphological examinations. Normal embryonic hearts treated with double-stranded MIR for 4 days show a dramatic reduction in tropomyosin protein and myofibrils. Hearts scanned here with dsRNA transfection already have stopped beating at the time of fixation. Hearts incubated with mock transfection (no dsRNA) show abundant staining of tropomyosin and organized myofibril structures $(A)$. Hearts transfected by dsRNA show almost no detectable expression of tropomyosin in the whole area of the ventricle (B). (Magnification: $60 \times$ ). 


\section{decrease after long term MIR knockdown following double-stranded RNA treatment}

On treatment with ds-RNA, we observed that a significant number of hearts stopped beating at days 3 and 4 . To determine the transcriptional levels of tropomyosin genes following ds-RNA treatment, we collected the total RNA from hearts treated with dsRNA and the negative controls (cultured in Lipofectin/Steinberg's solution only, with no dsRNA) after a 2-day transfection period with dsRNA (24 to 48 hours before significant decreases of tropomyosin protein were observed). Gene expression levels were then analyzed for both alpha-tropomyosin and TM4 type tropomyosin as well as the endogenous MIR. We observed that the endogenous expression of MIR was knocked down about $80 \%$ in normal hearts 36 or 84 hours after dsRNA transfection compared to the negative controls (Fig. 8A). It should be noted that a gradual decrease of MIR expression in untreated hearts was observed relative to in vitro culture times which is consistent with our earlier reports that MIR expression decreases progressively during in vivo development [7]. Two of the major isoforms of tropomyosin expressed in axolotl hearts alphatropomyosin (ATmC-1 and ATmC-2) and TM4 type tropomyosin (ATmC-3), interestingly, were not significantly reduced at the transcriptional level after a short period of treatment with double-stranded MIR (Fig. 8).

However, after collecting RNA samples from hearts organcultured for 9 days with either dsRNA or the no RNA controls, we found that both the alpha-tropomyosin and TM4 type tropomyosin decreased in mRNA levels in our realtime RT-PCR assays (Fig. 8). No significant changes in the tropomyosin expression levels were observed in dsRNAtreated hearts compared to the mock-transfected normal hearts (no dsRNA) in alpha-tropomyosin (ATmC-1 and ATmC-2) and TM4 type tropomyosin total RNA transcripts at either 36 hours or 84 hours post-transcription. A confirmation of the effect of double-stranded RNA transfection was shown by down regulation of the endogenous MIR to $1 / 4^{\text {th }}$ (36 hours) to $1 / 5^{\text {th }}$ ( 84 hours) dsRNA transfection (Fig. 8A). Decreased expression levels for both types of tropomyosin have also been detected in the 9day-cultured hearts compared to the hearts cultured for only 36 or 84 hours.

These results indicate that MIR possibly influences tropomyosin gene expression by an indirect regulatory mechanism. We also showed that decreasing the tropomyosin protein level in normal hearts after double-stranded MIR treatment is not due to changes of alpha-tropomyosin (ATmC-1 and 2) or TM4 tropomyosin (ATmC-3) mRNAs, but rather due to a failed translational or posttranslational control.
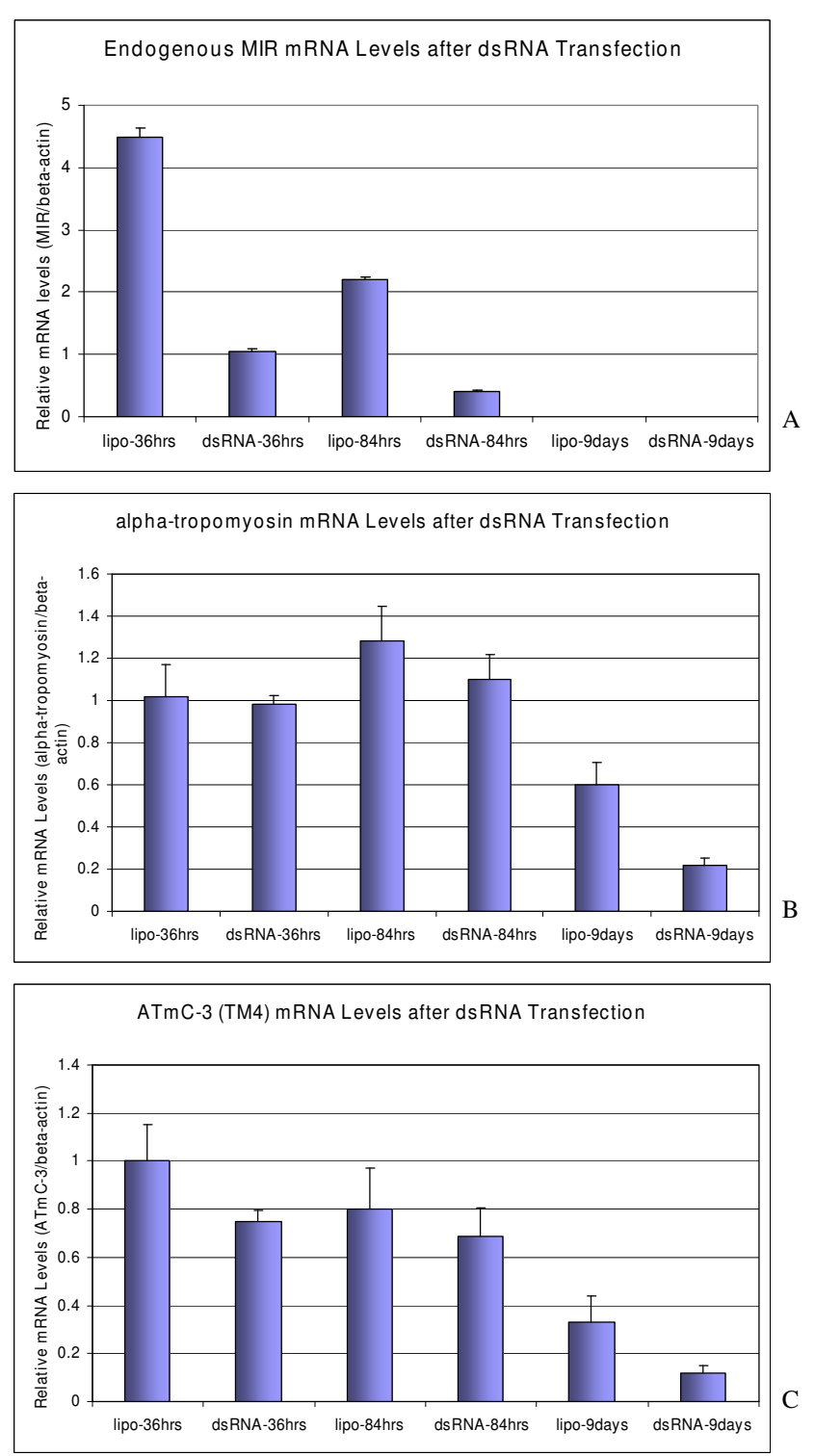

\section{Figure 8}

Determination of myofibril protein expression. Realtime RT-PCR confirms the knockdown of endogenous MIR (A) in the normal hearts but shows no significant difference at the level of the transcripts of alpha- (B) and TM4 type tropomyosin $(C)$ transcripts in the normal hearts treated with double-stranded MIR (dsRNA-) for 36 hours or 84 hours. However, both alpha- and TM4 type tropomyosin transcripts in the normal hearts treated with dsRNA for 9 days show dramatic decreases to nearly $1 / 3$ of the levels in control groups with hearts incubated in lipofectamine transfection medium only. MIR expression in 9-day-cultured hearts is not detectable. 
The reduced expression of tropomyosin may be related to the differential regulation of MIR of various tropomyosin isoforms in normal and mutant hearts

With the observation of normal control of tropomyosin expression at the mRNA level in mutant hearts, we have extended our studies of tropomyosin expression at the protein level. To determine whether multiple isoforms of tropomyosin exist in embryonic axolotl hearts and to verify if they are differentially expressed in mutant hearts, we used two-dimensional Western blotting experiments. Using a monoclonal antibody (CH1), developed to recognize sarcomeric type tropomyosin specifically [30], we have detected five different protein spots (tropomyosin isoforms) from both normal and mutant embryonic hearts at stages 36 to 42 (Fig. 9). All isoforms of tropomyosin detected by the $\mathrm{CH} 1$ antibody are located between $\mathrm{pI}$ 4 to 5 with molecular weight of approximately $38 \mathrm{kD}$. As shown in the Fig. 9C, D, we have found that, the protein levels of all the isoforms are significantly decreased in the mutant hearts compared to the normals. The No. 2 protein spot is barely shown in the enlarged blot but we can clearly see this spot in the overexposed film as shown in the right top corner (inset) of Fig. 9D. With reference to protein spot number 5 , it was not detectable in either normal or mutant heart samples at stage 36 (initiation of normal heartbeat stage). However, at stage 42, the number 5 protein spot was prominent in normal heart samples but nonexistent in mutant hearts.

As shown in Fig. 9, we have observed an isoform switch between embryonic hearts at stage 36 (Fig. 9D) and stage 42 (Fig. 9G). The stage 36 hearts predominantly express isoform 1 while the stage 42 hearts express isoforms 2 and 5. To further confirm the active translational activity for tropomyosin proteins in mutant hearts, we have treated the mutant hearts with the cysteine-protease inhibitor, $\mathrm{N}$ acetyl-leucine-leucine-norleucinal (LLnL, Calbiochem, San Diego, CA). The LLnL is a membrane-permeable proteinase inhibitor that inhibits Calpain and proteosome and has been reported to affect tropomyosin turnover in other cell culture systems [31]. All tropomyosin isoforms, except for No. 1, show significant increases in both normal and mutant hearts after incubating with LLnL for 10 hours. Using another lyosomal cysteine proteinase inhibitor, E-64d (Sigma, St. Louis, WA), which inhibits Calpain but not proteosome, interestingly showed increased expression of all isoforms including No.1 (Fig. 9I). These results suggest that different tropomyosin isoforms are degraded by different proteinases.

To confirm the increased expression level of tropomyosin protein after sense MIR treatment of mutant hearts, we conducted 2D Western blotting experiments using protein samples from mutant hearts treated with sense or antisense MIR for 4 days. (Fig. 9D, H and 9J), show that anti- sense MIR treatment decreases the amount of tropomyosin isoform 1 in mutant hearts without altering isoforms 3, 4 and 5. A significant increase of isoform 2, one of the major isoforms of tropomyosin in the embryonic heart at stage 42, is also detected. However, an unexpected loss of isoform 5 is observed in the sense MIRtreated mutant heart sample. These results unequivocally prove that MIR post-transcriptionally controls tropomyosin expression in embryonic hearts. In normal and mutant heart samples, irrespective of stage or MIR treatment, isoform 4 is always detectable with negligible alteration in expression, indicating that it probably has a housekeeping function.

\section{MIR promotes expression of myofibril structural protein genes}

From the previous experiments it is clear that MIR has a significant influence on the expression of tropomyosin in the developing heart which is known to play a major role in mechanically stabilizing actin filaments [32]. In this investigation we extended our gene expression studies to determine whether MIR promotes the expression of myofibril structural genes other than tropomyosin, such as, $\alpha$-myosin heavy chain, myosin-binding C-protein and cardiac troponin $\mathrm{T}$ and $\alpha$-syntrophin (one of the dystrophin-associated proteins), in normal and mutant hearts (Fig. 10). For the real-time RT-PCR experiments, primer pairs for each gene were designed in the intronflanking exon sequences to avoid PCR amplifications from genomic DNA contaminants. A significant increase in the mRNA of $\alpha$-MHC, C-protein, cTnT and $\alpha$-syntrophin were observed after 36 hours of incubation of mutant hearts (stage 37-38) with sense MIR, but not with antisense RNA. However, the effects of MIR treatment diminished after 72 hours, indicating possible degradation of MIR in the heart cells (Fig. 10G). On the other hand, p53 and Msx-1 genes, both being cell differentiation-related genes, show increased expression in the mutant hearts after 72 hours of MIR treatment, indicating an indirect or long term effect of MIR on promoting embryonic cardiomyocyte differentiation.

In summary, there are three categories of myofibril structural genes that respond to the treatment of MIR differently at their mRNA level: 1) genes that can be quickly (36 hours) up-regulated in transcription by MIR sense RNA treatment ( $\alpha$-MHC, C-protein, cTnT and $\alpha$-syntrophin); 2 ) genes that can be slowly ( 72 hours) up-regulated by MIR sense RNA treatment (p53 and Msx-1); and 3) genes that are not affected by MIR treatment (cardiac actin, $\beta$ syntrophin and ATmC-1, -2 and -3 ).

\section{Discussion}

Our research on the MIR gene has been the first to demonstrate that a small RNA is involved in the regulation of 

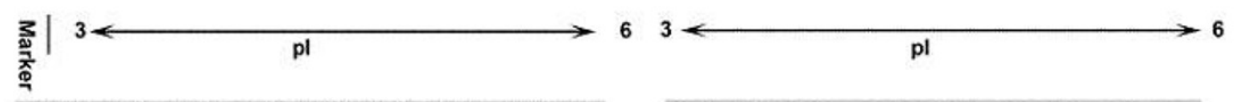

A.

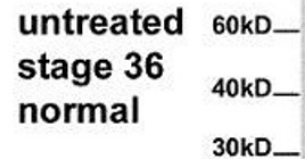

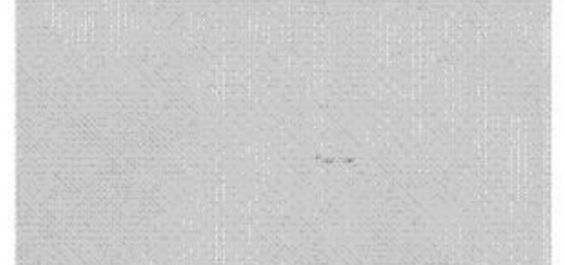

B.

untreated stage 36

mutant

C.

enlarged stage 36 untreated normal

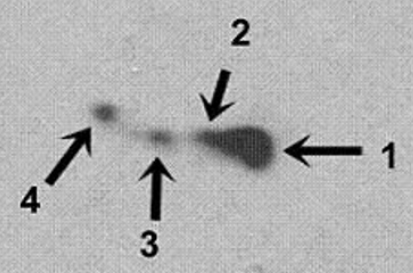

E.

\section{stage 36 normal + LLnL}

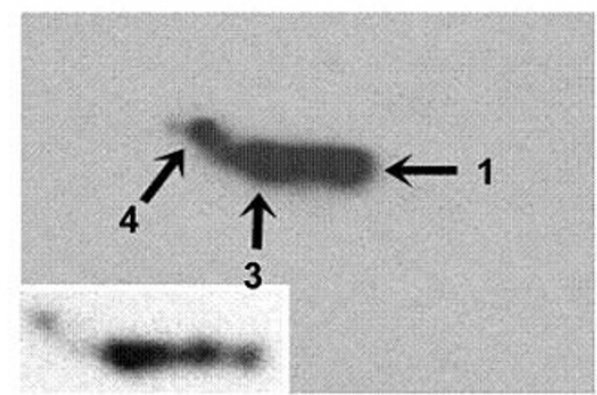

G.

untreated stage 42 normal

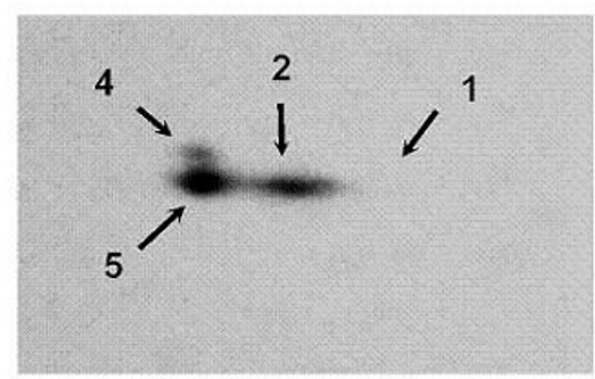

I.

stage 42
normal
+ E64d

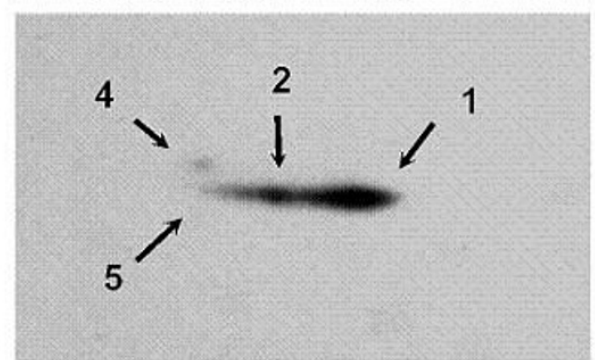

D. enlarged stage 36 untreated mutant

F.

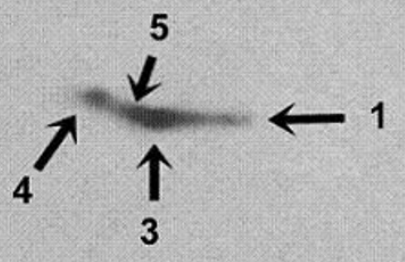
stage 36 mutant + LLnL

4
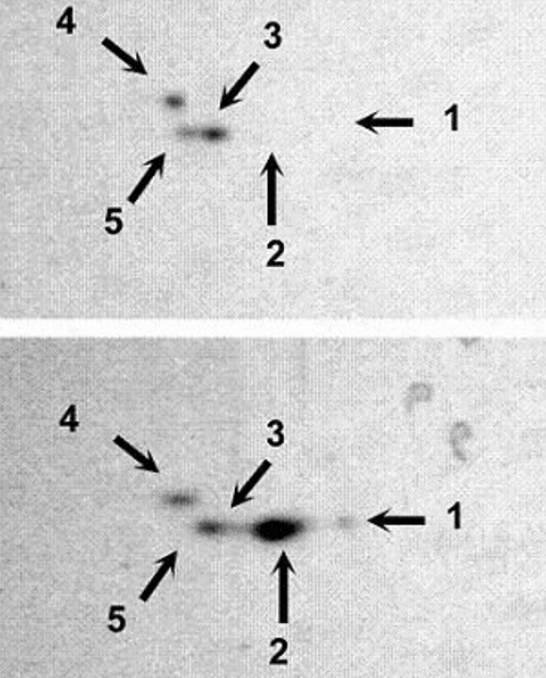

H. stage 36 mutant tantisense MIR

J. stage 36 mutant +sense MIR

Figure 9 (see legend on next page) 
Figure 9 (see previous page) Two-dimensional SDS-PAGE of embryonic heart proteins followed by Western Blotting using CH I (anti-tropomyosin) antibody. Untreated stage 36 normal hearts (A); Untreated stage 36 mutant hearts (B); Enlarged figure from $A$ for $\mathrm{CHI}$-recognizable tropomyosin isoforms in untreated normal hearts (C); Enlarged figure from $\mathrm{B}$ for $\mathrm{CHI}$-recognizable tropomyosin isoforms in untreated normal hearts $(D)$; The top right corner after overexposure of the same blot as $D$ shows that mutant hearts are expressing isoform 2 as well as isoforms I, 3 and 4. Mutant hearts at this stage are expressing all of the isoforms as normal hearts at much lower levels along with an extra isoform (5) which is detectable only at later developmental stages in normal hearts (G); Stage 36 normal hearts incubated with LLnL for 10 hours. The left bottom corner shows the less exposed image after Western blotting on the same sample, clearly showing increased protein concentration for isoform 2,3 and 4 but not for I (E); Stage 36 mutant hearts incubated with LLnL for 10 hours. Increasing of protein concentration for isoform 3, 4 and 5 is clearly detected but not for I (F); Untreated stage 42 normal hearts (G); Stage 42 normal hearts incubated with E64d for 10 hours (I); Protection for isoform I is detected. Stage 36 mutant hearts treated by antisense MIR for 4 days $(\mathrm{H})$; Stage 36 mutant hearts treated by sense MIR for 4 days $(\mathrm{J})$; A significant increase in spot density for isoform 2 is detected when compared to untreated mutant hearts at the same stage (D).

embryonic heart development in the cardiac mutant (gene c) of Ambystoma mexicanum. In the case of the MIR gene, since we now know that the MIR is a polyadenylated RNA, there is reason to believe that it may function through its unique secondary structure to promote myofibrillogenesis in the mutant hearts. We favor this hypothesis for the following reasons: First, the RNA used for rescuing experiments (either $650 \mathrm{nt}$ full length or $166 \mathrm{nt}$ clone \#4 RNA) was not processed for translation by capping or polyadenylation before it was added to the heart cultures implying that it lacked necessary machinery for translation inside the cells. The possibility that the active RNA rescues mutant hearts by providing mRNA that is translated is unlikely. Second, although there are several small open reading frames (ORF) predicted for the full length gene (the longest ORF is shown in Fig. 1), the shortest RNA we have shown to preserve bioactivity (140 nt with 26 nt deleted from the 3' end of $166 \mathrm{nt}$ Clone \#4 sequence shown with an underline in Fig. 1) does not cover the whole ORF [33]. Thus, the chance of this RNA being translated in the cells is virtually nonexistent.

Recently, there have been numerous tissue-specific and embryonic stem cell-expressed microRNAs cloned from mouse, some of which are heart specific [34,35]. Prior to our finding on the MIR $[7,11]$ there had been no previously reported non-coding RNAs important for heart development). In fact, the MIR gene appears to be the first non-coding RNA that has been reported to be involved in the process of anterior endoderm inducing precardiac mesoderm to form functional cardiac muscle tissue [36]. Further characterization is underway to rule out the possibility of MIR as being a typical miRNA and/or consider as a piRNA [37-39] or some other unique regulatory RNA molecule.

One of the long term objectives of our studies is to find the mammalian homolog of the MIR gene and study related pathways in mammals, including human.
Although some of the noncoding RNAs, such as some micro RNAs, are conserved between species, there are others that have many variations [40]. Based on sequence similarity, we have not yet identified the mammalian MIR homolog gene from a database search although we have preliminary data indicating that both sheep heart [7] and human heart (our unpublished data) contain functional MIR homologs which are able to promote myofibrillogenesis and rescue the mutant axolotl hearts. Recently, Mummery et al. [41] have indicated that there exists a very similar, probably identical, induction mechanism for mouse heart development from signals secreted from cultured mouse visceral endoderm-like cells. This factor has been found to be capable of promoting beating cardiomyocyte differentiation and beating in human embryonic stem cell cultures, indicating a non-protein factor secreted from mouse visceral endoderm cells, possibly the mouse homolog of our MIR gene. Thus, these results and findings from our studies in the animal model, Ambystoma mexicanum, suggest that the relationship between endoderm and heart induction is genetically conserved across the vertebrate species.

We have previously demonstrated that the MIR (166 nt core sequence) can bind to more than one protein. The MIR gene and its binding proteins are apparently involved in the regulation of tropomyosin expression [7]. Prior to current studies, it was not clear whether the failure of tropomyosin expression in mutant hearts takes place at the transcriptional level or the translational level and which isoform(s) of tropomyosin is/are significantly reduced in the mutant embryonic hearts. Our results in this study prove unequivocally that the MIR and, perhaps, its binding protein(s) work together to regulate tropomyosin expression translationally or posttranslationally in the mutant hearts since our studies did not detect transcriptional or splicing pattern differences in tropomyosin genes between normal and mutant embryonic hearts. Moreover, sequencing of the full-length cDNAs of both 

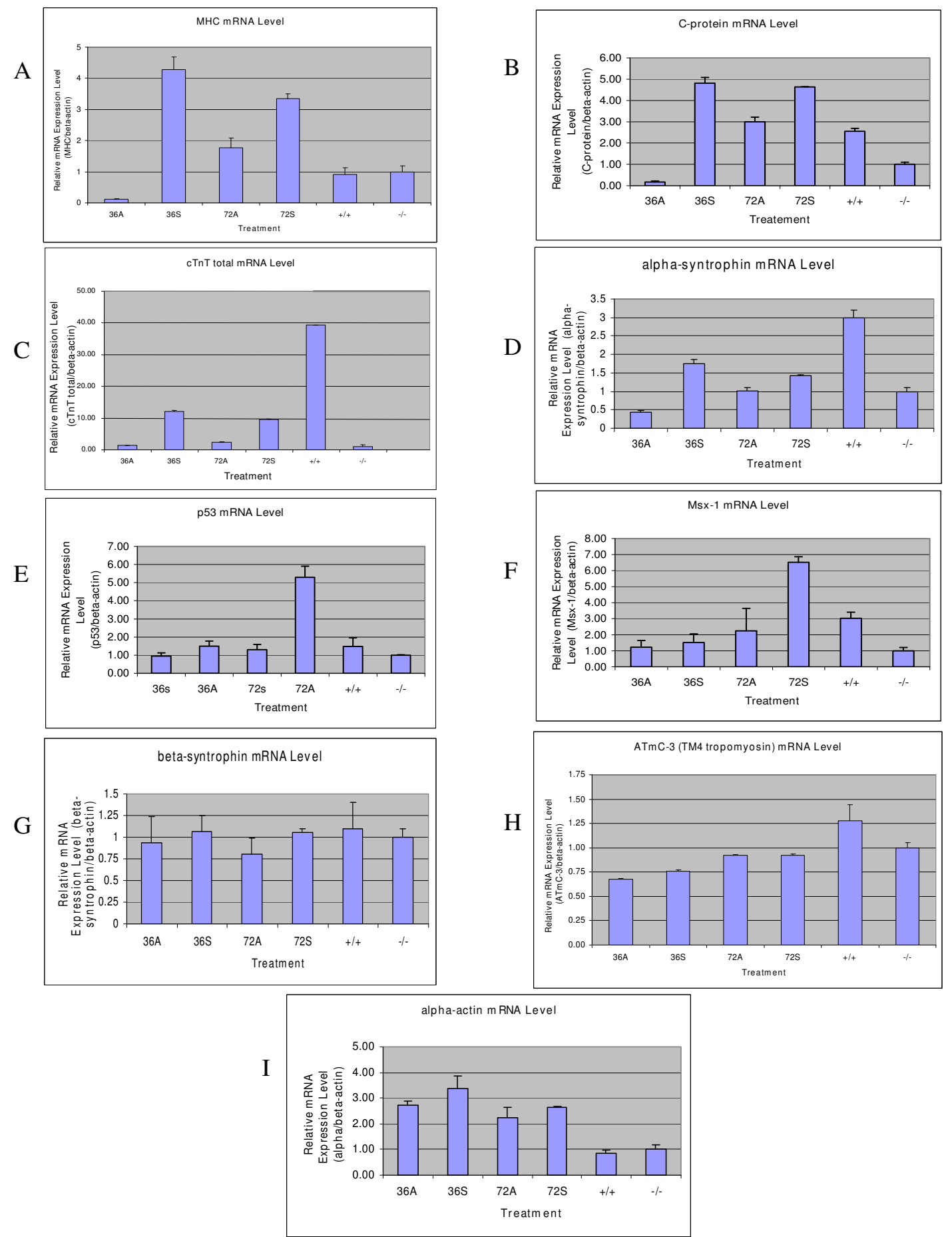

\section{Figure 10}

Real-time RT-PCR of myofibril genes on total RNA from stage 35-37 embryonic hearts treated by MIR. Relative expression levels of different genes were compared after normalizing by beta-actin mRNA levels. 36A: antisense MIR treated for 36 hours; 36S: sense MIR treated for 36 hours; 72A: antisense MIR treated for 72 hours; $72 S$ : sense MIR treated for 72 hours; -/-: homozygous mutant hearts with no treatment; +/+: homozygous normal hearts with no treatment. Alpha-MHC (A), C-protein (B), cardiac troponin T (C), alpha-I-syntrophin (D), p53 (E), Msx-I (F), beta-I-syntrophin (G), ATmC-3 (H), cardiac actin (I). 
alpha-tropomyosin and ATmC-3 from the embryonic hearts of both normal and mutant axolotls showed no differences reiterating the possible non-existence of splice variants of these genes in mutant hearts.

In addition to its significance for studying the basic mechanisms of myofibrillogenesis, irregularities in tropomyosin expression have also been shown to have clinical significance. There have been a number of reports indicating that familial cardiomyopathy can be caused by mutations in the tropomyosin gene itself [42-44]. Homozygous alpha-TM knockout mice are embryonic lethal [45]. Therefore, the cardiac mutant axolotl, with its deficiency in tropomyosin and its ability to be corrected, is potentially a very important model system for studying regulation of tropomyosin isoforms. It is clear from our analyses of the cardiac lethal mutant axolotl, that gene ' $c$ ' does not control early heart morphogenesis since the heart appears to form normally at pre-heartbeat stages [46]. However, the expression of tropomyosin is significantly reduced at the heartbeat stage (stage 35) [47]. Moreover, fewer isoforms of tropomyosin are detectable in embryonic mutant hearts by two-dimensional gel electrophoresis as compared to normal hearts [4]. This tropomyosin deficiency is intriguing given the current understanding of tropomyosin genetics and expression $[16,17,25,44,48]$. Despite these numerous studies, the mechanisms of tropomyosin gene regulation in cardiac tissues are not completely understood.

In addition to the identification of tissue specific transcription factors that regulate different tropomyosin gene transcription and specific intron/exon splicing regulatory sequences and factors that control alternative splicing, there are numerous recent findings that show both translational and posttranslational (sorting and protein turnover) control on tropomyosin proteins. For example, Rethinasamy et al. [45] have shown that translational regulation plays a major role in tropomyosin expression. In heterozygous knockout mouse hearts with a $50 \%$ reduction in cardiac muscle $\alpha$-TM mRNA, no compensatory increase in transcript levels were found for striated muscle $\beta$-TM or TM-30 isoforms. However, normal amounts of striated muscle $\alpha$-TM protein are produced and integrated into the myofibril, suggesting a mechanism for adjusting translational levels in functioning mouse hearts.

Besides the sorting mechanism for specific tropomyosin isoform subcellular localization, proteinase degradation is another important regulatory mechanism in the posttranslational control of tropomyosin. In non-muscle normal rat kidney (NRK) cells, it has been reported that large molecular weight tropomyosin proteins are degraded faster than smaller molecular weight tropomyosin proteins indicating different proteinases are involved in their proteolysis [31]. The stress fiber component tropomyosin degradation in normal cells or under growth factor treatment can be blocked by LLnL, a proteinase inhibitor to lysosomal cathepsins B and L, cytoplasmic calpains I and II [49] and proteasomes. However, using inhibitors that block calpains but not proteasomes does not block TM degradation [50]. These results indicate that striated muscle myofibril structural tropomyosins, stress-fiber high molecular weight tropomyosins and small molecular weight non-muscle tropomyosins are degraded by different proteinases within the cell. In our studies using axolotl heart tissue, we have also shown that LLnL can prevent degradation of some striated muscle tropomyosin proteins ( $\mathrm{CH} 1$ antibody recognizable) but not all, especially isoform number 1 that has increased expression along with heart development but has not been protected from the degradation by LLnL. Another Proteinase inhibitor, E64d, inhibits Calpain activities but not proteosome activites and thus protects a different subset of tropomyosin isoforms including isoform number 1 in the embryonic hearts.

In our mutant axolotl system, the decreased translational level of tropomyosin protein, abnormal tropomyosin sorting and significantly higher rates of protein degradation of the tropomyosin protein could all exist as a potential foundation for this mutant phenotype. However, recent studies on mutant hearts with normal ATmC-1, ATmC-2 and ATmC-3 tropomyosin cDNA transfected constructs, clearly show reorganization of myofibril structures, indicating the possible existence of a sorting mechanism in mutant cardiomyocytes [20,51].

Two possible mechanisms by which MIR promotes tropomyosin synthesis and myofibrillogenesis in the mutant axolotl hearts might include:

1. A mechanism whereby the MIR enters the mutant heart cells, is transported into the nucleus, perhaps together with its binding protein(s) [7], and promotes gene transcription of the various myofibril components. The MIR could as well regulate RNA splicing processes for these genes as indicated in our studies on cardiac troponin $\mathrm{T}$ [23]. The myofibrillogenesis is thus promoted with increased expression of building blocks of myofibrillar proteins. While the nascent myofibrillar structures may incorporate tropomyosin proteins and protect them from being degraded in MIR treated hearts, it is possible that those proteins, existing in unprotected monomer form in the untreated hearts, get degraded by unknown proteinase(s).

2. A second possibility might be that MIR and its binding proteins promote gene expression followed by translation of protein products that facilitate the translation of the 
mRNA of tropomyosin and possibly others, thus providing the essential building blocks for myofibrillogenesis. It is very unlikely that MIR and its binding proteins directly promote tropomyosin translation, since it takes 3-4 days after MIR transfection before increased tropomyosin expression and myofibril formation is observed in the mutant heart cells.

Recent studies show that short double-stranded RNA duplexes trigger post-transcriptional gene silencing and can also induce epigenetic silencing of genes at the level of transcription [52]. They can also interact at promoter regions and can activate or repress gene expression [53] or affect translation without affecting transcription [54].

While studies on siRNAs and miRNAs were extensively conducted in a wide variety of systems, comparatively, no remarkable studies were reported on small RNAs especially those that are similar to MIR. Recently, Makarev et al. [55] identified several miRNAs and small RNAs from adult newt eye, 42 of which have no similarity with known miRNAs or piRNAs. Our studies also clearly suggest that our MIR has no sequence homology with any of these known RNAs. Furthermore, none of the known small RNAs, to our knowledge, have been shown to regulate myofibrillogenesis similar to MIR. However, miRNAs on the other hand have been implicated as regulators of transcription as well as translation in a wide variety of systems $[54,56]$.

Although such reports indicate the regulatory role of different small RNAs at the transcription and/or translational levels, the underlying molecular mechanisms, however, are still poorly understood. Whatever the final mechanism of action of MIR turns out to be, it is very clear that MIR promotes tropomyosin synthesis and myofibrillogenesis in the mutant hearts and is essential for tropomyosin expression and myofibrillogenesis in normal hearts. We are conducting several experiments to isolate functional mouse/human homologues of MIR for further characterization. We assume also that MIR, or an MIRtype functional homologue, is involved in cardiomyocyte precursor cell differentiation in all vertebrate species.

\section{Competing interests}

The authors declare that they have no competing interests.

\section{Authors' contributions}

CZ designed and carried out many of the experiments in the study. He cloned and sequenced the full length DNA for the MIR and conducted the real-time RT-PCR experiments. PJ worked on the molecular biology and tissue culture experiments contributing significantly to both areas. $\mathrm{XH}$ was involved in the planning of the experiments and the immunofluorescent studies for tropomyosin in the
MIR rescued hearts. He also played a major role in writing the manuscript for publication. GFS participated in the analysis of the different tropomyosin isoforms in the determination of myofibril protein expression in the embryonic hearts. GA conducted and oversaw MIR rescue experiments and performed many of the immunofluorescent studies as well as real-time PCR studies. MPA provided guidance in the selection and data presentation and analysis. He also wrote significant portions of the manuscript. JW participated in the analysis of many of the immunofluroescent images and participated in writing the immunofluorescent sections of the manuscript. SL designed the mating protocols for the animal colony to obtain the time-staged embryos/tissues for the studies. In addition, she oversaw the preparations of the figures as well as the text of the manuscript. DKD was involved in the original design of the experiments for the study and participated in organizing the data to be included in the manuscript. In addition, he contributed significantly to the writing of the manuscript for publication. LFL served as the Principle Investigator on the study and the grants that supported the study. He oversaw all of the experiments in the study and coordinated the research activities of the study. He wrote/edited the entire manuscript and is the communicating author of the paper. All authors read and approved the final manuscript.

\section{Acknowledgements}

This study was supported by NIH grant HLO6 I 246 and by a Christine E. Lynn American Heart Association Grant-in-Aid to L.F.L. Some of the embryos used for this study were purchased from the Axolotl Colony at the University of Kentucky (NSF-DBI-0443496).

The content of this publication is solely the responsibility of the authors and does not necessarily represent the official views of the National Heart, Lung and Blood Institute or the National Institutes of Health.

\section{References}

I. Humphrey RR: Genetic and experimental studies on a mutant gene (c) determining absence of heart action in embryos of the Mexican axolotl (Ambystoma mexicanum). Dev Biol 1972, 27:365-375.

2. Lemanski LF: Role of tropomyosin in actin filament formation in embryonic salamander heart cells. J Cell Biol 1979, 82:227-238.

3. Moore PB, Lemanski LF: Quantitation of tropomyosin by radioimmunoassay in hearts of cardiac mutant axolotls, Ambystoma mexicanum. J Musc Res And Cell Motil 1982, 3:161-167.

4. Starr CM, Diaz JG, Lemanski LF: Analysis of actin and tropomyosin in hearts of cardiac mutant axolotls by two-dimensional gel electrophoresis, western blots, and immunofluorescent microscopy. J Morphol 1989, 20 I: I-I0.

5. LaFrance SM, Lemanski LF: Imunofluorescent confocal analysis of tropomyosin in developing hearts of normal and cardiac mutant axolotls. Int J Devel Biol 1994, 38:695-700.

6. Zajdel RW, Zhu Y, Fransen ME, Lemanski LF: A primary cell culture model for defective cardiac myofibrillogenesis in Mexican axolotl embryos. In Vitro Cell Dev Biol Anim 1997, 33:677-680.

7. Zhang C, Dube DK, Huang X, Zajdel RW, Bhatia R, Foster D, Lemanski SL, Lemanski LF: A point mutation in bioactive RNA results in the failure of mutant heart correction in Mexican axolotls. Anat Embryol 2003, 206:495-506. 
8. Lemanski LF, Mooseker MS, Peachey LD, lyengar MR: Studies of muscle proteins in embryonic myocardial cells of cardiac lethal mutant mexican axolotls (Ambystoma mexicanum) by use of heavy meromyosin binding and sodium dodecyl sulfate polyacrylamide gel electrophoresis. J Cell Biol 1976, 68:375-388.

9. Erginel-Unaltuna N, Dube DK, Lemanski LF: Protein synthesis during heart development in normal and cardiac mutant axolotls. Axol Newsletter 1994, 23:48-60.

10. Ward SM, Dube DK, Fransen ME, Lemanski LF: Differential expression of C-protein isoforms in the developing heart of normal and cardiac lethal mutant axolotls (Ambystoma mexicanum). Dev Dyn 1996, 205:93-103.

II. Lemanski LF, Nakatsugawa M, Bhatia R, Erginel-Unaltuna N, Spinner B], Dube DK: A specific synthetic RNA promotes cardiac myofibrillogenesis in the Mexican axolotl. Biochem Biophys Res Commun 1996, 229:974-98I.

12. Hook J, Lemckert F, Qin H, Schevzov G, Gunning P: Gamma tropomyosin gene products are required for embryonic development. Mol Cell Biol 2004, 24:23 I 8-2323.

13. Vlahovich N, Schevzov G, Nair-Shaliker V, Ilkovski B, Artap ST, Joya JE, Kee AJ, North KN, Gunning PW, Hardeman EC: Tropomyosin 4 defines novel filaments in skeletal muscle associated with muscle remodeling/regeneration in normal and diseased muscle. Cell Motil Cytoskeleton 2008, 65:73-85.

14. Zhao L, Zhao X, Tian T, Lu Q, Skrbo-Larssen N, Wu D, Kuang Z, Zheng X, Han Y, Yang S, Zhang C, Meng A: Heart-specific isoform of tropomyosin 4 is essential for heartbeat in zebrafish embryos. Cardiovasc Res 2008, 80:200-208.

15. Grenklo S, Hillberg L, Rathje LZ, Pinaev G, Schutt CE, Lindberg U: Tropomyosin assembly intermediates in the control of microfilament system turnover. Eur J Cell Biol 2008, 87:905-920.

16. Muthuchamy M, Boivin GP, Grupp IL, Wieczorek DF: Beta-tropomyosin overexpression induces severe cardiac abnormalities. J Mol Cell Cardiol 1998, 30:1545-1557.

17. Hardy S, Theze N, Lepetit D, Allo MR, Thiebaud P: The Xenopus laevis TM-4 gene encodes non-muscle and cardiac tropomyosin isoforms through alternative splicing. Gene 1995, 1 56:265-270.

18. Luque EA, Spinner BJ, Dube S, Dube DK, Lemanski LF: Differential expression of a novel isoform of alpha-tropomyosin in cardiac and skeletal muscle of the Mexican axolotl (Ambystoma mexicanum). Gene 1997, 185:175-180.

19. Spinner BJ, Zajdel RW, McLean MD, Denz CR, Dube S, Mehta S, Choudhury A, Nakatsugawa M, Dobbins N, Lemanski LF, Dube DK: Characterization of a TM-4 type tropomyosin that is essential for myofibrillogenesis and contractile activity in embryonic hearts of the Mexican axolotl. J Cell Biochem 2002, 85:747-76I.

20. Zajdel RW, McLean MD, Lemanski SL, Muthuchamy M, Wieczorek DF, Lemanski LF, Dube DK: Ectopic expression of tropomyosin promotes myofibrillogenesis in mutant axolotl hearts. Dev Dyn 1998, 213:412-420.

2I. Zajdel RW, McLean MD, Isitmangil G, Lemanski LF, Wieczorek DF, Dube DK: Alternation of cardiac myofibrillogenesis by liposome-mediated delivery of exogenous proteins and nucleic acids into whole embryonic hearts. Anat Embryol 2000, 201:217-228.

22. Jia $P$, Zhang C, Huang XP, Poda M, Akbas F, Lemanski SL, Erginel-Unaltuna N, Lemanski LF: A novel protein involoved in heart development in Ambystoma Mexicanum is localized in endoplasmic reticulum. J Biomed Sci 2008, I 5:789-799.

23. Sferrazza GF, Zhang C, Jia P, Athauda G, Dube S, Lemanski SL, Dube DK, Lemanski LF: Role of Myofibril-Inducing RNA in cardiac TnT expression in developing Mexican axolotl. Biochem Biophys Res Com 2007, 357:32-37.

24. Cho YJ, Hitchcock-DeGregori SE: Relationship between alternatively spliced exons and functional domains in tropomyosin. Proc Natl Acad Sci USA 1991, 88:10153-10157.

25. Helfman DM, Berthier C, Grossman J, Leu M, Ehler E, Perriard E, Perriard JC: Non-muscle tropomyosin-4 requires coexpression with other low molecular weight isoforms for binding to thin filaments in cardiomyocytes. I Cell Sci 1999, I I 2:37 I-380.

26. Goodwin LO, Lees-Miller JP, Leonard MA, Cheley SB, Helfman DM: Four fibroblast tropomyosin isoforms are expressed from the rat alpha-tropomyosin gene via alternative RNA splicing and the use of two promoters. J Biol Chem 1991, 266:8408-84I5.

27. Lin JJ, Chou CS, Lin JL: Monoclonal antibodies against chicken tropomyosin isoforms: production, characterization, and application. Hybridoma 1985, 4:223-242.

28. Vogt VM: Purification and further properties of single-strandspecific nuclease from Aspergillus oryzae. Eur J Biochem 1973, 33:192-200.

29. Fransen MF, Lemanski LF: Epicardial development in the axolotl, Ambystoma mexicanum. Anat Rec 1990, 226:228-236.

30. Lin JJ, Lin JL: Assembly of different isoforms of actin and tropomyosin into the skeletal tropomyosin-enriched microfilaments during differentiation of muscle cells in vitro. J Cell Biol 1986, 103:2173-2183.

3I. Warren RH: TGF-alpha-induced breakdown of stress fibers and degradation of tropomyosin in NRK cells is blocked by a proteasome inhibitor. Exp Cell Res 1997, 236:294-303.

32. Ujfalusi Z, Vig A, Hild G, Nyitrai M: The effect of topomyosin on formin-bound actin filaments. Biophys J 2009, 96:162-168.

33. Lemanski LF, Zajdel RW, Nakasugawa M, Bhatia R, Spinner BJ, Fransen ME, Gaur AF, McLean MD, Lemanski SL, Dube DK: Molecular biology of heart development in the Mexican axolotl, Ambystoma mexicanum. Tsitologiia 1997, 39:918-927.

34. Lagos-Quintana M, Rauhut R, Yalcin A, Meyer J, Lendeckel W, Tuschl $\mathrm{T}$ : Identification of tissue-specific microRNAs from mouse. Curr Biol 2002, I 2:735-739.

35. Houbaviy HB, Murray MF, Sharp PA: Embryonic stem cell-specific MicroRNAs. Dev Cell 2003, 5:35I-358.

36. Thum T, Catalucci D, Bauersachs J: MicroRNAs: novel regulators in cardiac development and disease. Cardiovasc Res 2008, 79:562-570.

37. Zucker M: Mfold web server for nucleic acid folding and hybridization prediction. Nucleic Acids Res 2003, 31:3406-34I5.

38. Grivna ST, Beyret E, Wang Z, Lin H: A novel class of small RNAs in mouse spermatogenic cells. Genes Dev 2006, 20:1709-17/4.

39. O'Donnell KA, Boeke JD: Mighty piwis defend the germline against genome intruders. Cell 2007, I29:37-44.

40. Sempere LF, Sokol NS, Dubrovsky EB, Berger EM, Ambros V: Temporal regulation of microRNA expression in Drosophila melanogaster mediated by hormonal signals and broadComplex gene activity. Dev Biol 2003, 259:9-18.

4I. Mummery C, Oostwaard DW, Doevendans P, Spijker R, Brink S van den, Hassink R, Heyden M van der, Opthof T, Pera M, de la Riviere $A B$, Passier R, Tertoolen L: Differentiation of human embryonic stem cells to cardiomyocytes: role of coculture with visceral endoderm-like cells. Circulation 2003, 107:2733-2740.

42. Watkins H, Anan R, Coviello DA, Spirito P, Seidman JG, Seidman CE: A de novo mutation in alpha-tropomyosin that causes hypertrophic cardiomyopathy. Circulation 1995, 91 :2302-2305.

43. Bing W, Redwood CS, Purcell IF, Esposito G, Watkins H, Marston SB: Effects of two hypertrophic cardiomyopathy mutations in alpha-tropomyosin, Aspl75Asn and Glul80Gly, on Ca2+ regulation of thin filament motility. Biochem Biophys Res Commun 1997, 236:760-764.

44. Prabhakar R, Boivin GP, Grupp IL, Hoit B, Arteaga G, Solaro JR, Wieczorek DF: A familial hypertrophic cardiomyopathy alpha-tropomyosin mutation causes severe cardiac hypertrophy and death in mice. J Mol Cell Cardiol 200I, 33:1815-1828.

45. Rethinasamy PM, Muthuchamy M, Hewett T, Arteaga G, Solaro JR, Wieczorek DF: Molecular and physiological effects of alphatropomyosin ablation in the mouse. Circ Res 1998, 82: I 16-123.

46. Fransen MF, Lemanski LF: Myocardial cell relationships during morphogenesis in normal and cardiac lethal mutant axolotls, Ambystoma mexicanum. Am J Anat 1988, 183:245-257.

47. Lemanski LF, LaFrance SM, Erginel-Unaltuna N, Luque EA, Ward SM, Fransen ME, Mangiacapra FJ, Nakatsugawa M, Lemanski SL, Capone RB, Goggins KJ, Nash BP, Bhatia R, Dube A, Gaur A, Zajdel RW, Zhu $Y$, Spinner BJ, Pietras KM, Lemanski SF, Kovacs CP, VanArsdale X, Lemanski JL, Dube DK: The cardiac mutant gene $c$ in axolotls: cellular, developmental, and molecular studies. Cell Mol Biol Res 1995, 4 1:293-305.

48. Gromak N, Rideau A, Southby J, Scadden AD, Gooding C, Hüttelmaier S, Singer RH, Smith CW: The PTB interacting protein raverI regulates alpha-tropomyosin alternative splicing. $E M B O$ J 2003, 22:6356-6364. 
49. Sasaki T, Kishi M, Saito M, Tanaka T, Higuchi N, Kominami E, Katunuma N, Murachi T: Inhibitory effect of di- and tripeptidyl aldehydes on calpains and cathepsins. J Enzyme Inhib 1990, 3:195-201.

50. Rock KL, Gramm C, Rothstein L, Clark K, Stein R, Dick L, Hwang D, Goldberg AL: Inhibitors of the proteasome block the degradation of most cell proteins and the generation of peptides presented on MHC class I molecules. Cell 1994, 78:76I-77I.

5I. Denz CR, Narshi A, Zajdel RW, Dube DK: Expression of a novel cardiac-specific tropomyosin isoform in humans. Biochem Biophys Res Commun 2004, 320:1291-1297.

52. Papenfort K, Vogel J: Multiple target regulation by small noncoding RNAs rewires gene expression at the post-transcriptional level. Res Microbiol 2009, 160:278-287.

53. Janowski BA, Younger ST, Hardy DB, Ram R, Huffman KE, Corey DR: Activating gene expression in mammalian cells with promoter-targeted duplex RNAs. Nature Chem Biol 2007, 3: 166-I73.

54. Zhu S, Si M, Wu H, Mo Y: MicroRNA-2I Targets the Tumor Suppressor Gene Tropomyosin I (TPMI). J Biol Chem 2007, 282: |4328-|4336.

55. Makarev E, Spence JR, Del Rio-Tsonis K, Tsonis PA: Identification of microRNAs and other small RNAs from the adult newt eye. Mol Vision 2006, I 2: I386-139|.

56. Luo X, Lin H, Pan Z, Xiao J, Zhang Y, Lu Y, Yang B, Wang Z: Downregulation of miR-1/miR-133 Contributes to Re-expression of Pacemaker Channel Genes HCN2 and HCN4 in Hypertrophic Heart. J Biol Chem 2008, 283:20045-20052.

Publish with Bio Med Central and every scientist can read your work free of charge

"BioMed Central will be the most significant development for disseminating the results of biomedical research in our lifetime. "

Sir Paul Nurse, Cancer Research UK

Your research papers will be:

- available free of charge to the entire biomedical community

- peer reviewed and published immediately upon acceptance

- cited in PubMed and archived on PubMed Central

- yours - you keep the copyright

Submit your manuscript here:

http://www.biomedcentral.com/info/publishing_adv.asp
BiolMedcentral 